\title{
Selective axonal translation of prenylated Cdc42 mRNA isoform
}

\section{supports axon growth}

Seung Joon Lee ${ }^{1}$, Amar N. Kar ${ }^{1}$, Riki Kawaguchi ${ }^{2}$, Priyanka Patel ${ }^{1}$, Pabitra K. Sahoo ${ }^{1}$, Byron Aguilar ${ }^{3}$, Kelsey D. Lantz ${ }^{1}$, Caylee R. McCain ${ }^{1}$, Giovanni Coppola ${ }^{2,4}$, Qun Lu ${ }^{3}$, Jeffery L. Twiss ${ }^{1}$

${ }^{1}$ Department of Biological Sciences, University of South Carolina, Columbia, SC 29208 USA

${ }^{2}$ Department of Psychiatry, Semel Institute for Neuroscience and Human Behavior, Los Angeles, CA 90095-1761, USA

${ }^{3}$ Department of Anatomy and Cell Biology, Brody School of Medicine, Eastern Carolina University, Greenville, NC 27834 USA

${ }^{4}$ Department of Neurology, Semel Institute for Neuroscience and Human Behavior, Los Angeles, CA 90095-1761, USA

Corresponding Author: Jeffery L. Twiss, M.D., Ph.D.

Dept. Biological Sciences

University of South Carolina

715 Sumter St., CLS 401

Columbia, SC 29208 USA

phone, (803)777-9215

fax, (803)777-4242

email,twiss@mailbox.sc.edu

Running Title: Axonal Cdc42 mRNA supports growth

Figures: 7 Figures, 2 Expanded View Figures, 1 Expanded View Table

Word Count: Abstract - 175 words 
SJ Lee et al.

Selective axonal localization of Cdc42 mRNA isoforms

\begin{abstract}
The small Rho-family GTPase CDC42 has long been known to have a role in cell motility and axon growth. The eukaryotic $C d c 42$ gene is alternatively spliced yielding mRNAs with two different $3^{\prime} U T R s$ and distinct C-termini, which have CaaX and CCaX motifs for post-translational prenylation or palmitoylation, respectively. Palmitoylated CDC42 protein has been shown to contribute to dendrite maturation, while the prenylated CDC42 protein contributes to axon specification. Here, we show that the mRNA encoding prenylated CDC42 protein preferentially localizes into axons of cultured sensory neurons. We show that prenylated CDC42 promotes axon growth in cultured sensory neurons, but palmitoylated CDC42 does not affect axon growth. The growth promotion by prenylated CDC42 requires axonal localization of its mRNA and an intact C-terminal CaaX motif for post-translational modification of the encoded protein by prenylation. Prenylated CDC42 protein localizes to the periphery of growth cones, but this subcellular localization requires axonal targeting of its mRNA. Together, these data show that alternative splicing of the $C d c 42$ gene product generates an axon growth-promoting, locally synthesized prenylated CDC42 protein.
\end{abstract}

Keywords: alternative splicing / axon regeneration / growth cone / mRNA transport / post-translational modification 
SJ Lee et al.

Selective axonal localization of Cdc42 mRNA isoforms

\section{INTRODUCTION}

Concentrating proteins in subcellular regions is used to create unique functional domains in polarized cells. This can be achieved by specifically transporting proteins from their sites of translation to subcellular regions through protein targeting sequences that are used for protein localization (Emanuelsson et al, 2007). Transport of mRNAs to subcellular domains with subsequent localized translation in those domains is also used to spatially regulate protein levels within polarized cells. For some mRNAs, this localized translation imparts unique functions to the cell. For example, localization of $\beta$-actin mRNA to the migratory front of fibroblasts provides directed cell movement during cell migration (Shestakova et al, 2001). These mechanisms have also been observed to occur in other cellular functions. For example, mRNAs encoding ribosomal proteins were recently shown to relocalize to the apical side of intestinal epithelium when fasted mice are fed (Moor et al, 2017).

As remarkably polarized cells with widely separated and specialized subcellular domains, neurons have provided a very useful model system to both profile the populations of mRNAs that are transported into their axons and dendrites, as well as to test functions of proteins synthesized locally in these compartments (Kar et al, 2018; Terenzio et al, 2017). Axons can extend to lengths that are more than 1000-fold longer than the neuron's cell body diameter, and localized synthesis of new proteins in distal axons provides a level of autonomy to respond to extracellular stimuli (Sahoo et al, 2018). For example, both growth-promoting and growth-inhibiting stimuli regulate intra-axonal protein synthesis to support directional growth of axons and axon branching (Rangaraju et al, 2017; Terenzio et al, 2017). RNA profiling studies have shown hundreds to thousands of mRNAs localized into axons of sensory, cortical, retinal ganglion cell, and motor neurons (see (Kar et al, 2017) for a recent review). These populations include several mRNAs encoding proteins that can modify the axonal cytoskeleton, either directly through generation of microfilament, intermediate filament, and microtubule precursors or 
SJ Lee et al.

Selective axonal localization of Cdc42 mRNA isoforms

indirectly by generation of proteins that regulate polymerization, depolymerization, severing, or branching of the cytoskeleton.

Previous work from the Jaffrey group has shown the mRNA encoding the small GTPase RHOA, whose activation has been shown to trigger axon retraction, localizes into and is translated within axons in response to the axon repelling stimulus Semaphorin 3a (Wu et al, 2005). RHOA belongs to the Rho GTPase family, that also includes cell division cycle 42 (CDC42) and RAC proteins. Rho GTPases regulate cytoskeleton organization and antagonistic functions among these family members have been reported in neurons (Etienne-Manneville \& Hall, 2002). For instance, RHOA activation leads to neurite retraction through an increase in actomyosin contractility and actin depolymerization, while CDC42 and RAC activation lead to neurite extension by promoting actin polymerization (Da Silva et al, 2003; Jalink et al, 1994; Luo, 2000; Luo et al, 1994). Intra-axonal translation of RhoA mRNA increases after exposure to Semaphorins and chondroitin sulfate proteoglycans (CSPG) triggering growth cone repulsion and/or collapse. Depleting RHOA from axons prevents this growth cone collapse allowing axons to grow on CSPGs (Walker et al, 2012a; Wu et al, 2005). These observations point to a role for intra-axonal mRNA translation in propagating the effects of growth inhibitory stimuli.

Here, we show that $C d c 42$ mRNA, whose protein product generates effects opposite of RhoA (Hall \& Lalli, 2010), is also translated in axons. The Cdc42 gene undergoes alternative splicing to generate two distinct Cdc42 mRNAs. We find that the mRNA encoding the prenylated CDC42 (preny/Cdc42; also known as the 'placental isoform'), but not the mRNA encoding the palmitoylated CDC42 isoform (palm-Cdc42; also known as the 'brain isoform'), localizes into axons and supports axon growth. The prenyl-Cdc42 and palm-Cdc42 mRNAs have distinct C-termini and 3'UTRs (Wirth et al, 2013), and the 3'UTR of the prenyl-Cdc42 mRNA drives its localization into axons. Both axonal localization of the prenyl-Cdc42 mRNA and an intact C-terminal CaaX motif for prenylation are needed to fully support axon growth. CDC42's contribution to axonal growth has been known for many years, and our data 
SJ Lee et al.

Selective axonal localization of Cdc42 mRNA isoforms

indicate that this function is uniquely driven by the prenyl-CDC42 isoform through axonal localization of the prenyl-Cdc42 mRNA and C-terminal modification of the locally translated protein product.

\section{RESULTS}

Prenyl-Cdc42 mRNA isoform uniquely localizes into axons - The rat Cdc42 gene consists of 7 exons that generate two mRNA isoforms by alternative splicing of exons six and seven (Fig 1A). The splice variant ending with exon six encodes the palm-Cdc42 mRNA that generates a palmitoylated protein. The splice variant where exon six is skipped to include exon seven encodes the ubiquitously expressed prenyl-Cdc42 mRNA that generates a prenylated protein (Wirth et al, 2013). Thus, these two Cdc42 mRNAs have different 3'UTRs and they encode proteins with distinct C-terminal 11 amino acids. This alternative splicing of the $C d c 42$ gene product is conserved from fish to mammals (Table EV1). Mining published RNA sequencing (RNA-seq) data from axonal RNA isolates shows that the prenyl-Cdc42 mRNA isoform is expressed at higher levels than the palm-Cdc42 mRNA isoform in cultured embryonic mouse sensory and motor neurons, but an overall higher proportion of the prenyl-Cdc42 mRNA appeared to localize into axons compared to the palm-Cdc42 mRNA (Fig EV1A-B) (Briese et al, 2016; Minis et al, 2014). RNA-seq data from adult mouse DRG cultures similarly show higher proportion of the prenylCdc42 mRNA in axons than the palm-Cdc42 mRNA (Fig EV1C). In contrast, published RNA-seq data for cortical neurons show near-equivalent proportions of prenyl-Cdc42 and palm-Cdc42 mRNAs in neurite preparations that contain both axons and dendrites (Fig EV1D). Together, these data suggest that $C d c 42$ mRNA isoforms are present in neuronal processes similar to what has been shown for RhoA mRNA (Walker et al, 2012b; Wu et al, 2005), with potentially preferential localization of the prenyl-Cdc42 mRNA into the axonal compartment. 
SJ Lee et al.

Selective axonal localization of Cdc42 mRNA isoforms

To determine if the prenyl-Cdc42 mRNA preferentially localizes into axons, we cultured L4-6 dorsal root ganglia (DRG) neurons from adult rat sensory neurons on a porous membrane to allow for purification of RNA from axons and cell bodies (Zheng et al, 2001). Reverse transcriptase-coupled polymerase chain reaction (RT-PCR) showed that the axonal preparations contained Actb but not somatodendritic Map2 mRNA, cell body-restricted c-Jun and H1fO mRNAs, or glial Gfap mRNA (Fig 1B). Using droplet digital RT-PCR (RT-ddPCR), comparable levels of palm-and prenyl-Cdc42 mRNAs were detected in the DRG cell body RNA preparations (Fig 1C). Prenyl-Cdc42 mRNA was relatively abundant in the axonal RNA isolates compared to palm-Cdc42 mRNA where only a few copies were detected (Fig 1C). Fluorescence in situ hybridization (FISH) also showed prenyl-Cdc42 mRNA signal in axons, but the axonal signal for palm-Cdc42 mRNA was comparable to a scrambled probe control (Fig 1D). Notably, the axonal FISH signals for the prenyl-Cdc42 mRNA appeared granular (Fig 1D) as has been described for transported neuronal mRNAs (Kar et al, 2018). Quantitation of these FISH signals showed significantly less palm-Cdc42 mRNA than palm-Cdc42 mRNA in the axons, with comparable cell body levels of these two mRNAs (Fig 1E-F). Thus, the prenyl-Cdc42 mRNA localizes into axons of adult rat sensory neurons, while the palm-Cdc42 mRNA is largely restricted to the soma.

Prenyl-Cdc42 3'UTR drives axon localization - Since axon-localizing motifs are often found in 3'UTRs (Andreassi \& Riccio, 2009; Gomes et al, 2014), we asked if the different 3'UTRs of palm-Cdc42 and prenyl-Cdc42 mRNAs, encoded by exons 6 and 7, respectively, are responsible for their distinct subcellular localization in the DRG neurons. Myristoylated (MYR) eGFP reporter constructs containing the 3'UTRs of prenyl-Cdc42 vs. palm-Cdc42 mRNAs (GFP ${ }^{\text {MYR }} 3^{\prime}$ palm-cdc42 and GFP ${ }^{\text {MYR }} 3^{\prime}$ prenyl-cdc42, respectively) were expressed in DRG cultures and FISH for GFP RNA was used to test for axonal localization. In these cDNA expression constructs and those used below, we refer to the 3'UTR as nt 731-1503 for palm-Cdc42 mRNA (NCBI RefSeq ID, XM_008764287.2) and nt 1147-2547 for prenyl- 
SJ Lee et al.

Selective axonal localization of Cdc42 mRNA isoforms

Cdc42mRNA (NCBI RefSeq ID, XM_008764286.2), while exons 6 and 7 consist of nt 641-1503 for palmCdc42 mRNA and 1057-2547 for prenyl-Cdc42 mRNA, respectively (with nt 641-697 in palm-Cdc42 and nt 1057 to 1113 in prenyl-Cdc42 encoding the same amino acids). Only the GFP ${ }^{\text {MYR }} 3^{\prime}$ prenyl-cdc42 transfected neurons showed detectable axonal GFP RNA signals (Fig 2A-C). Axonal FISH signals for $G F P^{M Y R} 3^{\prime}$ palm-Cdc42 mRNA were not significantly different than those of the GFP ${ }^{M Y R}$ mRNA carrying the 3'UTR of $\gamma$-actin mRNA that has been previously shown not to localize into DRG axons (Willis et al, 2007). Thus, the 3'UTR from CDC42 exon 7 that is only included in the prenyl-Cdc42 mRNA is sufficient for axonal mRNA localization.

Alternative splicing of the $C d c 42$ gene product accounts for the different $3^{\prime} U T R s$ of the endogenous prenyl- and palm-Cdc42 mRNAs. The GFPMYR constructs used above would not be subjected to these splicing events, and retention of proteins at splice sites or exon junctions has been suggested to impact subcellular localization and/or translation of the endogenous mRNAs (Le Hir et al, 2016). To address this possibility, we generated $C d c 42$ 'mini-gene' constructs that include GFP cDNA fused to rat Cdc42 exons 4, 5 and 6 or exons 4, 5 and 7 (Fig EV2A). Exons 4 and 5 were separated by the endogenous 103 nucleotide (nt) intervening intron; exons 5 and 6 or 5 and 7 were separated by a 500 nt intronic sequence downstream of exon 5 and plus 500 nt intronic upstream of exon 6 or 7 . By RT-PCR, DRGs transfected with these mini-gene constructs showed PCR products at the anticipated sizes of the mature RNA for GFP + Cdc42 exons 4-6 and GFP + Cdc42 exons 4-5 + 7 (Fig EV2B). By FISH, GFP mRNA in cell bodies showed comparable levels for DRG neurons transfected with either the mini-gene $(G F P+C d c 42$ exons 4-6 and GFP + Cdc42 exons 4-5 and 7) and GFP cDNA + 3'UTRs of prenyl-Cdc42 and palm-Cdc42 constructs (Fig EV2C). Robust axonal localization was seen for the mini-gene construct containing Cdc42 exon 7 and the GFP-3'prenyl-Cdc42 cDNA constructs (Fig EV2D). mRNAs from neither the mini-gene containing CDC42 exon 6 or the GFP-3'palm-Cdc42 showed significant axonal localization above the GFP control construct (Fig EV2D), which we have previously shown does not localize into axons (Merianda et 
SJ Lee et al.

Selective axonal localization of Cdc42 mRNA isoforms

al, 2013). These data further emphasize that 3'UTR sequences encoded by exon 7 of the Cdc42 gene are necessary and sufficient for axonal localization, and this explains the more robust axonal localization of prenyl-Cdc42 compared to palm-Cdc42 mRNA.

We next asked whether the 3'UTR of prenyl-Cdc42 supports translation of the mRNA in axons by transfecting DRG neurons with the GFP ${ }^{M Y R} 3^{\prime}$ prenyl-cdc42 and GFP MYR $3^{\prime}$ palm-cdc42. The MYR tag of the GFP markedly limits diffusion of the protein in neurites so that sites of protein synthesis in dendrites and axons can be visualized using fluorescence recovery after photobleaching (FRAP) (Aakalu et al, 2001; Yoo et al, 2013; Yudin et al, 2008). FRAP studies revealed that distal axons of DRGs expressing GFP ${ }^{M Y R} 3^{\prime}$ prenyl-cdc42 mRNA showed significantly higher GFP MYR recovery after photobleaching than those expressing GFP MYR 3 'palm-cdc42 mRNA (Fig 2D-E). Pre-incubation with the translation inhibitor anisomycin attenuated the post-bleach fluorescent recovery, indicating that the axonal GFP ${ }^{\mathrm{MYR}} 3^{\prime}$ prenylcdc42 fluorescent recovery derives from protein that is locally synthesized in these axons (Fig 2D-E). The GFP $^{\text {MYR }} 3^{\prime}$ palm-cdc42 did show more recovery than GFP ${ }^{M Y R} 3^{\prime} \gamma$-actin transfected neurons, which is consistent with the low axonal levels of palm-cdc42 mRNA seen by RT-ddPCR in Fig 1C. Nonetheless, these data show that the different 3'UTRs in prenyl-Cdc42 vs. palm-Cdc42 mRNAs are responsible for the preferential axonal localization of prenyl-Cdc42 mRNA in adult rodent sensory neurons.

Axonal prenyl-Cdc42 mRNA drives axon growth - CDC42 protein has been shown to localize to growth cones and its activation supports neurite outgrowth (Matsuura et al, 2004; Myers et al, 2012). Recent work linked the prenyl-CDC42 protein isoform to axon specification in CNS neurons while the palmCDC42 protein isoform was needed for dendritic spine development (Yap et al, 2016). To determine whether axonal localization of prenyl-Cdc42 mRNA contributes to the known growth effects of CDC42 protein, we selectively knocked down prenyl-vs. palm-CDC42 or both using pan and isoform-specific siRNAs (siCdc42, siPrenyl and siPalm; Fig 3A). RT-ddPCR analyses showed that the pan siCdc42 depleted 
SJ Lee et al.

Selective axonal localization of Cdc42 mRNA isoforms

both Cdc42 mRNA isoforms (Fig 3B-C) and decreased axon growth in the DRG cultures (Fig 3D-E). The siPalm depleted palm-Cdc42 mRNA with no effect on prenyl-Cdc42 mRNA level (Fig 3B-C). siPrenyl depleted prenyl-Cdc42 mRNA by more than 70\%, but the palm-Cdc42 mRNA was also $40-50 \%$ decreased by the siPrenyl transfections (Fig 3B-C). siPrenyl significantly decreased axonal growth, at levels comparable to depletion of both mRNA isoforms using pan siCdc42, but the siPalm had no apparent effect on axon outgrowth (Fig 3D-E)

The comparable effect of siCdc42 and siPrenyl on axon outgrowth would be consistent with the notion that axonally localizing prenyl-Cdc42 mRNA selectively supports axon growth. However, we could not rule out contributions of the palm-Cdc42 mRNA isoform to axon growth given that its levels were decreased by both siCdc42 and siPrenyl transfections. Thus, we tested the ability of siRNA-resistant ('siresistant') prenyl-Cdc42 and palm-Cdc42 constructs as GFP fusion proteins to rescue the decrease in axonal growth seen after pan-siCdc42 transfection (Fig 4A). Axon growth was only fully rescued by expressing the si-resistant prenyl-Cdc42 mRNA with its axonally localizing 3'UTR (Fig 4B-C). There was no rescue when the si-resistant prenyl-Cdc42 mRNA included the 3'UTR of the GFP construct (Fig 4B-C), which we had previously shown does not localize into DRG axons (Merianda et al, 2015). The siresistant palm-Cdc42 mRNA similarly did not rescue the axon growth deficit in the siCdc42-transfected DRGs (Fig 4B-C). Consistent with these results, pharmacological activation of Cdc42 increased axon growth but this effect was lost in DRGs transfected with pan-siCdc42 or siPrenyl but not siPalm (data not shown). Taken together, these data indicate that the axonally localizing prenyl-Cdc42 mRNA, and not the non-localizing palm-Cdc42 mRNA, supports axon growth in adult sensory neurons. Notably, branching of axons was not affected by knockdown of CDC42 or rescue transfections with si-resistant prenylCDC42 or palm-CDC42 constructs (Fig 4D), indicating that CDC42 contributes to axon elongation and not axon branching. 
bioRxiv preprint doi: https://doi.org/10.1101/366369; this version posted July 10, 2018. The copyright holder for this preprint (which was not certified by peer review) is the author/funder. All rights reserved. No reuse allowed without permission.

SJ Lee et al.

Selective axonal localization of Cdc42 mRNA isoforms

\section{Axonal RNA localization and prenylation motif of prenyl-Cdc42 mRNA are needed for optimal axonal}

outgrowth - Although only differing by 11 amino acids, unique functions for prenyl- and palm-CDC42

protein isoforms in neurons have been reported in previous studies (Kang et al, 2008; Yap et al, 2016).

We wondered if distinct subcellular localization of prenyl-Cdc42 and palm-Cdc42 mRNAs in the DRG

neurons contributes to these unique functions and asked if targeting the palm-Cdc42 mRNA into axons

would affect axon growth. For this, we generated si-resistant palm-CDC42 expressing cDNAs with its

3'UTR replaced by the axonal-targeting prenyl-Cdc42 3'UTR (Fig 5A). Pan-siCdc42 transfected DRG

neurons showed partial rescue of axon growth with expression of the axonally-targeted si-resistant

palm-Cdc42 mRNA (Fig 5B). This observation suggests that either CDC42 isoform can support axon

growth, but only the axonally targeted prenyl-Cdc42 mRNA can fully rescue the axon growth deficit seen

with knockdown of both CDC42 isoforms.

With different degrees of rescue by axonally targeted prenyl-vs. palm-Cdc42 mRNAs, we next

asked whether the post-translational prenylation or palmitoylation accounts for the growth promoting effects of the axonally targeted prenyl-Cdc42 mRNA. The first 180 amino acids of palm-Cdc42 and prenyl-Cdc42 proteins are identical, with the distinct C-terminal 11 amino acids encoded by exons 6 and 7, respectively. The four C-terminal residues of these two Cdc42 isoforms contain CCaX and CaaX motifs for palmitoylation and prenylation, respectively (where $\mathrm{C}$ represents cysteine, $\mathrm{a}$ is an aliphatic amino acid and $X$ is any amino acid) (Wirth et al, 2013). The cysteines in the CaaX and CCaX motifs are covalently modified by prenylation and palmitoylation (Nishimura \& Linder, 2013), and mutating the cysteine residues to serine has been used to prevent these post-translational modifications (Wirth et al, 2013). The CCaX motif in the palm-Cdc42 protein product (CCIF) can undergo an initial prenylation at the first cysteine followed by palmitoylation at the second cysteine (Wirth et al, 2013). Thus, we generated si-resistant mutants for palm-Cdc42 with its C-terminal CCIF mutated to CSIF, SCIF, and SSIF and for prenyl-Cdc42 with its C terminal CVLL mutated to SVLL to block post-translational modifications 
SJ Lee et al.

Selective axonal localization of Cdc42 mRNA isoforms

of these protein (Fig 5A). Both the prenyl-Cdc42 and palm-Cdc42 mRNAs were targeted into the axons using the 3'UTR of prenyl-Cdc42 mRNA. The axonally targeted, si-resistant palm-Cdc42 SCIF and SSIF mutants did not significantly increase axon growth in the pan-siCdc42 transfected neurons (Fig 5B). Axonally-targeted si-resistant prenyl-Cdc42 SVLL mRNA and palm-Cdc42 with intact CCIF motif showed partial rescue of axon growth in pan-siCdc42 transfected DRG cultures as compared to axonally targeted, si-resistant prenyl-Cdc42 with intact CVLL motif at its C-terminus (Fig 5B). Taken together, these data suggest that both axonal mRNA localization and the post-translational prenylation are needed for the full axon growth-promoting effects of the prenyl-CDC42 isoform, with the palm-CDC42 isoform only partially supporting axon growth when it is targeted into axons. Notably, axon branching did not show any significant change by expression of the either wild type or mutant CDC42 constructs (Fig 5C).

Prenyl-Cdc42 and Palm-Cdc42 proteins show distinct localizations in growth cones - Since axonally targeted palm-Cdc42 mRNA with intact C-terminal CCIF motif did not promote axon growth to the same extent as prenyl-Cdc42 mRNA, we asked if prenyl-CDC42 and palm-CDC42 proteins show different localization along axons or within growth cones. We used high resolution confocal microscopy to visualize GFP-tagged prenyl-CDC42 and palm-CDC42 proteins in distal axons and growth cones of DRG neurons transfected with CDC42 constructs with or without axonally localizing 3'UTR encoded by Cdc42 exon 7 (Fig 6A). The protein product of the axonally targeted GFP-prenyl-Cdc42 mRNA showed fluorescent signals concentrated at the periphery of the growth cone, frequently with what appeared to be localization just beneath the axoplasmic membrane (Fig 6B-C). In contrast, GFP-prenyl-Cdc42 mRNA with C-terminal CVLL to SVLL mutation, which prevents prenylation of the protein product, showed lower signals in the growth cone and rare concentrated signals (Fig 6D-E). Removing the axonaltargeting 3'UTR from GFP-prenyl-Cdc42 mRNA gave protein signals that were similarly low in the growth cone and rarely concentrated at the growth cone periphery (Fig 6F-G); since this mRNA would contain a 
SJ Lee et al.

Selective axonal localization of Cdc42 mRNA isoforms

3'UTR from the GFP construct, it would be expressed and translated as the GFP signals in axon shaft clearly show. Interestingly, targeting GFP-palm-Cdc42 mRNA into axons using the prenyl-Cdc42 3'UTR showed GFP signals that were quite similar to the prenyl-CDC42 SVLL mutant and cell body-restricted GFP-prenyl-Cdc42 expressing neurons (Fig 6H-I). Robust GFP signals were observed along the axon shafts for each of these proteins (Fig 6B-I). Thus, we conclude that the distinct localization of GFPprenyl-CDC42 to the periphery of growth cones is determined by both its axonal translation and intact CaaX motif.

\section{DISCUSSION}

Intra-axonal protein synthesis has been shown to contribute to axon growth during development and regeneration, and thousands of mRNAs are now known to localize into axons in vitro (Kar et al, 2018). Though most studies on axonal protein synthesis have used cultured neurons, there is increasing evidence for protein synthesis in axons in vivo during development and after injury (Akins et al, 2017; Brittis et al, 2002; Jin et al, 2016; Kalinski et al, 2015; Shigeoka et al, 2016; Walker et al, 2012a; Willis et al, 2011). Our data indicate that the mRNA for the prenylated isoform of CDC42, and not the palmitoylated CDC42 isoform, localizes into axons where its protein product promotes axon growth. With roles in actin polymerization and filopodia formation, CDC42 protein function has long been linked to axon growth and cell migration (Hall \& Lalli, 2010). The palm-CDC42 and prenyl-CDC42 isoforms are generated by alternative splicing with differential inclusion of exons 6 and 7 in the mature mRNA isoforms, respectively (Chen et al, 2012). Studies in cultured CNS neurons has pointed to differential roles for the palm-CDC42 and prenyl-CDC42 isoforms in dendrite maturation and axon specification, respectively (Yap et al, 2016). Our data emphasize that axonal mRNA targeting through use of Cdc42 gene's exon 7 and axonal translation of the resulting mRNA are responsible for CDC42's axon growth promoting functions. Interestingly, many mRNAs that localize into axons are also translated in the soma, 
SJ Lee et al.

Selective axonal localization of Cdc42 mRNA isoforms

with the soma-derived protein product being transported into axons. Consistent with this, both the prenyl-CDC42 and palm-CDC42 proteins localize into axons when expressed with a cell body-restricted 3'UTR.

Alternative RNA splicing can increase the number of different proteins that can be generated from a single gene. Subcellular localization of mRNAs is most frequently driven by sequence motifs in 3'UTRs (Andreassi \& Riccio, 2009; Gomes et al, 2014). Previous studies showed that Importin $\beta 1$, RanBP1, Stat $3 \alpha$ and $B D N F$ mRNA isoforms with long $3^{\prime} U T R s$ can be selectively transported into neuronal processes (An et al, 2008; Ben-Yaakov et al, 2012; Perry et al, 2012; Yudin et al, 2008). Alternative polyadenylation site usage generates the 'long $3^{\prime}$ UTR' variants of those mRNAs such that an RNA localization motif is presumably introduced from the additional 3'UTR sequences. RNA-seq from neurites of neuronally differentiated mouse neuroblastoma (N2A) and catecholaminergic neuronal tumor (CAD) cell lines recently showed a prevalence for distal alternative last exons and additional exon usage over differential poly-adenylation site usage for subcellularly targeted mRNA isoforms (Taliaferro et al, 2016). This prevalence was similarly seen for localizing mRNA isoforms in neurites from cultures of primary cortical neuron as well as axons from embryonic DRG neuron cultures. Moreover, Taliaferro et al. (2016) observed a shift of alternative splicing to favor mRNA isoforms with localizing 3'UTRs during neuronal differentiation of CAD cells (Taliaferro et al, 2016). Although inclusion of CDC42 exon 7 rather than exon 6 selectively generates a $C d c 42$ mRNA isoform with axonally localizing $3^{\prime} U T R, C d c 42$ expression shifts from generating predominantly prenyl-Cdc42 mRNA to predominantly palm-Cdc42 mRNA during brain development (Makeyev et al, 2007). Indeed, palm-CDC42 has been referred to as the 'brain Cdc42' isoform while prenyl-CDC42 is referred to as the 'placental Cdc42' isoform (Nicole et al, 1999), suggesting tissue specific functions for these differentially modified Cdc42 isoforms. The RNA-binding protein PTBP1 attenuates alternative splicing in non-neuronal cells by control of 5' splice site usage (Hamid \& Makeyev, 2014). PTBP1 was shown to suppress splicing of $C d c 42$ exon 6, making prenyl-Cdc42 
SJ Lee et al.

Selective axonal localization of Cdc42 mRNA isoforms

mRNA the dominant splice variant when PTBP1 is expressed, and palm-Cdc42 mRNA the dominant splice variant when PTBP1 is not expressed (Makeyev et al, 2007). Expression of miR-124 that targets PTBP1 mRNA increases during brain development such that PTBP1 levels fall as the nervous system develops (Hamid \& Makeyev, 2014). Interestingly, RNA-seq profiles from cultured embryonic motor and sensory as well as adult sensory neurons show higher levels of prenyl-Cdc42 than palm-Cdc42 mRNAs (Briese et al, 2016; Minis et al, 2014) (Figure EV1). In contrast to the maturing brain, these cultured neurons continuously extend axons, so it is possible that continued use of $C d c 42$ exon 7 helps to drive axon growth by generating prenyl-Cdc42 mRNA that localizes into growing axons.

Axonal CDC42 activity is increased by the axon growth-promoting BDNF and laminin and decreased by the chemo-repellant Slit2 (Myers et al, 2012; Wong et al, 2001; Yuan et al, 2003). Neuronal CDC42 has been shown to contribute to axon initiation, axon growth, and growth cone guidance (Hall \& Lalli, 2010). For example, selective localization of RAP1b and CDC42 at the tip of the presumptive axon is essential to initiate axon growth and establish polarity of neurons (Schwamborn \& Puschel, 2004). Linking CDC42 functions to axon growth has often relied on constitutively active or dominant negative mutations of CDC42 or depletion of both CDC42 isoforms as we have done in Figure 3 (Banzai et al, 2000; Chandran et al, 2016; Nishimura et al, 2005). Overexpression of a single Rho GTPase was shown to competition for with endogneous RhoGTPases for binding to RHOGDI1, and this alter levels of those other RhoGTPases (Boulter et al, 2010). Thus interpretation of studies using overexpression of dominant negative and constitutively active CDC42 mutants is complicated by this competition mechanism. Moreover, the expression constructs for these CDC42 mutants did not contain the axonally localizing 3'UTR encoded by Cdc42 exon 7 that would be needed to distinguish effects of palm-CDC42 and prenyl-CDC42 isoforms as we have used here. CDC42 proteins derived from the cell body-restricted palm-Cdc42 mRNA and prenyl-Cdc42 mRNA carrying the cell body-restricted GFP 3'UTR clearly get transported into distal axons. It will be interesting to consider if roles previously ascribed to 
SJ Lee et al.

Selective axonal localization of Cdc42 mRNA isoforms

CDC42 in axon specification and growth cone guidance are from the axonally translated prenyl-Cdc42

mRNA. Both BDNF and Slit2 have been shown to regulate protein synthesis in axons (Ming et al, 2002;

Piper et al, 2006), so we speculate that CDC42's role in axon guidance could be carried out by intraaxonal translation of prenyl-Cdc42 mRNA.

Recent work from the Makeyev lab showed differential functions of palm-CDC42 and prenylCDC42 for dendrite and axon growth from hippocampal neurons using isoform specific overexpression and knockdown/knockout approaches (Yap et al, 2016). Specifically, their data showed that prenylCDC42 is required for development of the axon while palm-CDC42 is needed for maturation of dendritic spines. This implies differential localization of the two proteins, with neuronal polarity determined by the balance of the two. Though in our hands only prenyl-Cdc42 mRNA localizes into axons, RNA-seq data from cortical neuron cultures shows that both prenyl- and palm-Cdc42 mRNA isoforms are present in neurites (Taliaferro et al, 2016). These preparations contain both axons and dendrites, so it is intriguing to speculate that palm-Cdc42 mRNA may localize into dendrites considering the relative absence of palm-Cdc42 mRNA from the axonal compartment. siRNA-based depletion of both CDC42 isoforms from hippocampal neuron cultures at DIV12 decreased dendritic spine numbers and this was rescued by expression of either prenyl-CDC42 or palm-CDC42 (Wirth et al, 2013). It is not clear if 3'UTRs for either the prenyl-Cdc42 or palm-Cdc42 mRNAs were included in the expression constructs used by Yap et al. (2016) and Wirth et al. (2013). Nonetheless, rescue of dendritic spine growth by prenyl-CDC42 and palm-CDC42 was lost with CaaX to AaaX mutation of prenyl-Cdc42 and CCaX to AAaX mutation of palm-CDC42 (Wirth et al, 2013), emphasizing the importance for post-translational modification of CDC42's C-terminus. Notably in our hands, both the palm-Cdc42 and prenyl-Cdc42 mRNAs localize into dendrites (data not shown), so it is quite feasible that localized synthesis of either CDC42 isoform can contribute to dendritic growth. 
bioRxiv preprint doi: https://doi.org/10.1101/366369; this version posted July 10, 2018. The copyright holder for this preprint (which was not certified by peer review) is the author/funder. All rights reserved. No reuse allowed without permission.

SJ Lee et al.

Selective axonal localization of Cdc42 mRNA isoforms

Prenylation and palmitoylation modifications of CDC42 proteins increase protein hydrophobicity and facilitate association with cellular membranes. The axonally translated prenyl-CDC42 protein showed increased localization to the periphery of growth cones compared to the more central locations for cell body synthesized prenyl-CDC42, axonally-targeted prenyl-Cdc42 with mutated CaaX motif, or palm-Cdc42 targeted into axons with the 3'UTR of prenyl-Cdc42. Consistent with the distinct subcellular localization for axonally synthesized prenyl-CDC42, an intact CaaX motif for prenylation of CDC42 is needed for the full growth promoting effects of the axonally targeted prenyl-Cdc42 mRNA. In contrast, the palm-Cdc42 mRNA did not support axon growth when targeted into axons to the same extent as the axonally targeted prenyl-Cdc42 mRNA. Isoprenoid lipid attachments to cysteine residues in the Cterminal CaaX motif of prenyl-CDC42 promotes its subcellular localization to the plasma membrane and other cellular membrane comparts including ER, Golgi, and endosomes (Roberts et al, 2008). PalmCDC42 and prenyl-CDC42 proteins have been shown to have different mobilities in cell membranes so they may be targeted to different membrane domains. The prenyl-transferases, farnesyl transferase (FT) and geranylgeranyl transferase (GGT), catalyze addition of either farnesyl or geranylgeranyl isoprenoid lipids to cysteine in the CaaX motif. Both prenyl-CDC42 and RHOA, which is also synthesized locally in axons (Wu et al, 2005), are substrates for GGT and not FT (Wirth et al, 2013). On the other hand, both cysteines in the CCaX motif of palm-CDC42 can be palmitoylated or the first cysteine prenylated by GGT followed by palmitoylation of the second cysteine (Nishimura \& Linder, 2013; Wirth et al, 2013). It is not clear which of these two modifications of palm-CDC42 occur in the DRG neurons. GGT and FT proteins have been detected in proteomics screens of growth cones from embryonic rat brains (Estrada-Bernal et al, 2012), so at least the terminal proteins needed for prenylation are present in distal axons. Based on previous publications, both CCIF and CSIF motifs would be substrates for GGT (Nishimura \& Linder, 2013; Wirth et al, 2013), and hence prenylation of locally synthesized CDC42 likely occurs in the growth cone. Thus, our mutation data suggest that palm-Cdc42 mRNA targeted into axons through 3'UTR of prenyl- 
SJ Lee et al.

Selective axonal localization of Cdc42 mRNA isoforms

Cdc42 likely undergoes prenylation as the axonal growth deficit was partially rescued by axonally targeted palm-Cdc42 mRNA with intact CCIF but not with the SCIF or SSIF mutations. Furthermore, the growth promoting effects of prenyl-Cdc42 mRNA were lost when the mRNA restricted to the soma by replacing the $3^{\prime} U T R$ with that of GFP.

In summary, our data indicate that the prenyl-CDC42 isoform specifically drives CDC42's axon growth promoting effects in adult sensory neurons though axonal translation of its mRNA. This growth promotion also requires an intact CaaX motif for post-translational prenylation of the axonally synthesized CDC42 protein. On first glance, our data seem to contradict a recent study that linked prenylation to slowed axon growth on myelin-associated glycoprotein (MAG), a substrate that inhibits axon growth (Li et al, 2016). In cultured neurons, highly-selective FT inhibitors were more effective than GGT inhibitors for increasing axon growth, but the combination of the two showed synergistic effects (Roberts et al, 2008). RHOA shows altered subcellular localization upon inhibition of GGT (Roberts et al, 2008), and in contrast to the growth promoting effects of prenyl-CDC42 shown here, RHOA attenuates axon growth on non-permissive substrates like MAG and the protein is synthesized in axons (Walker et al, 2012b; Wu et al, 2005). Previous studies have shown compensatory geranylgeranylation through GGT for some farnesylated GTPases when FT is inhibited (Roberts et al, 2008), which could account for the increased efficacy of FT plus GGT inhibition seen by Li et al. (2016). Our analyses of a single prenylated protein points to support of axon growth by this post-translational modification, but only when the protein is locally synthesized in axons. So global inhibition of prenylation may have distinct effects on axon growth from prenylation of locally synthesized proteins in axons.

\section{MATERIALS AND METHODS}

Animal use and neuron cultures - All animal experiments were conducted under IACUC approved protocols. For DRG cultures, L4-6 ganglia were isolated from adult male Sprague Dawley rats (175-250 g) 
SJ Lee et al.

Selective axonal localization of Cdc42 mRNA isoforms

and dissociated with collagenase (Invitrogen). Cells were washed and then plated with DMEM/F12

(Cellgro) supplemented with $10 \%$ fetal bovine serum (Gemini Bio), $10 \mu \mathrm{M}$ cytosine arabinoside (Sigma) and N1 supplement (Sigma). Cells were cultured on either glass coverslips or polyethylene-tetrathalate (PET) membrane (1 $\mu$ m pores; Corning) inserts coated with poly-L-lysine (Sigma) and laminin (Millipore).

DRG cultures were transfected with 2-3 $\mu$ g of plasmids using Amaxa Nucleofection device (Lonza) with Basic Neuron SCN Nucleofector kit (Program SCN-8) before plating and maintained for $48-72 \mathrm{~h}$. For depletion experiments, synthetic siRNAs (predesigned from IDT, $100 \mathrm{nM}$ ) were transfected into DRG neurons using DharmaFECT 3 and incubated for 3 DIV. For control, identical amounts of non-targeting siControl pools were used. RT-ddPCR was used to test the efficiency of depletion (see below). siRNA sequences were: siPrenyl (\#1), 5' GUGUUGUCAUCAUACUAAAAGCAAU 3'; siPrenyl (\#2), 5' GCAAUgUUUAAAUCAAACUAAAGAU 3'; siPalm (\#1), 5' GUGAUCAGUAGUCACAUUAGACUUG 3'; siPalm (\#2), 5' UCAGUAGUCACAUUAGACUUGUUUA 3'; siCdc42, 5' UgGUAAAACAUGUCUCCUG 3'.

Plasmid constructs - All fluorescent reporter constructs for analyses of RNA translation were based on eGFP with myristoylation element (GFP ${ }^{\text {MYR }}$; originally provided by Dr. Erin Schuman, Max-Plank Inst., Frankfurt) (Aakalu et al, 2001). To isolate the cDNA of rat Cdc42 (NCBI RefSeq ID: XM_008764286 for prenyl-Cdc42; XM_008764287 for palm-Cdc42), total RNA from rat DRG was reverse transcribed with SuperScript II (Invitrogen) and then amplified by PCR using PrimeStar HS polymerase (Takara). Primers for amplifying the prenyl-Cdc42 coding sequence and 3'UTR were engineered to contain terminal Not I and Sal I restriction sites. Using these restriction sites, the amplicons were then inserted into pEGFP-C3 (Clontech) vectors. Quikchange site-directed mutagenesis kit (Stratagene) was used to introduce point mutations of CaaX or CCaX motifs.

Fluorescence in situ hybridization and immunofluorescence - Myristoylated EGFP was fused with 3'UTRs of Cdc42 isoforms to test their axonal localization. Transfected DRG neurons were fixed 15 min in 4\% paraformaldehyde (PFA) and hybridized with DIG-labeled GFP cRNA probes (Roche) as described 
SJ Lee et al.

Selective axonal localization of Cdc42 mRNA isoforms

previously (Merianda et al, 2013). Sheep anti-DIG (1:100; Roche, \# 11333089001) was used to detect probes with Cy5-conjugated donkey anti-sheep (1:200; Jackson Immunoresearch, \# 713-095-003). Endogenous Cdc42 isoforms were detected with 5' Cy5-labelled Stellaris probes (probe sequences available upon request; Biosearch Tech).

For immunofluorescence, neurons plated on glass coverslips were fixed with $4 \%$ paraformaldehyde in PBS for 15 min at room temperature. Cultures were permeabilized with $0.3 \%$ Triton X-100 in PBS for 15 min and incubated with primary antibodies for overnight in humidified chambers at $4^{\circ} \mathrm{C}$. Chicken anti-NF (1:1,000; Aves labs, \# NFL, NFM and NFH) was used for labelling neurons and FITC-conjugated donkey anti-chicken (1:200; Jackson Immunoresearch, \# 703-095-155) were used as secondary antibodies. For visualization of GFP-tagged Cdc42 proteins in growth cones, rabbit anti-GFP (1:500; Abcam, \# ab6556) and chicken anti-NF (1:1,000, Aves labs) was used for primary antibodies and FITC-conjugated donkey anti-rabbit (1:200; Jackson Immunoresearch, \# 711-095-152) and Cy5-conjugated donkey anti-chicken (1:200; Jackson Immunoresearch, \# 703-175-155) were used as secondary antibodies. Coverslips were washed with PBS and then incubated with secondary antibodies for an hour before mounting with Prolong anti-fade mounting solution (Invitrogen).

For analyses of FISH signals, images were obtained using an epifluorescence microscope equipped with ORCA ER CCD camera (Hamamatsu) using matched acquisition parameters (exposure time and gain). Pixel intensities were measured from distal axons from more than 50 neurons in three replicate experiments. GFP signals in the growth cone were detected by Leica SP8X confocal microscope with HyD detectors. Z-stack images were post-processed by Huygens deconvolution (Scientific Volume Imaging) integrated into the Leica LASX software (HyVolution). Deconvolved image stacks were projected into single plane images using the maximum pixel intensities.

RNA isolation and PCR analyses - RNA was isolated from dissociated DRG neurons or cell body/axon compartments collected from insert cultures using RNeasy Micro kit (Qiagen). Purified RNAs were 
SJ Lee et al.

Selective axonal localization of Cdc42 mRNA isoforms

quantified with Ribogreen (Invitrogen) and 10-50 ng of RNA were used for reverse transcription with SensiFAST CDNA synthesis kit (Bioline) according to the manufacturer's protocol. To assess the purity of axonal RNA, RT-PCR was performed with primers designed to detect cell body-restricted mRNAs (c-Jun, H1fO, Map2) and glial cell-specific mRNAs (Gfap). ddPCR was performed according to manufacturer's procedure (Biorad) with either Evagreen (Biorad) or Taqman probe assays (Integrated DNA Tech). Hmgb1 mRNA levels were used for normalizing RNA yields across different isolates; we have previously shown that cell body and axonal RNA levels of Hmgb1 mRNA do not change after axotomy (Merianda et al, 2015).

Axon growth analyses - For analyses of axon growth, dissociated DRGs grown on glass coverslips or glass bottom 24 well plates were immunostained with neurofilament antibodies as described above. Entire coverslip or bottom of the 24 well plates were scanned with ImageXpress Micro system (Molecular Devices) using a 20X objective. Stitched images were assessed for total axon length, longest axon length, and branching using WIS-Neuromath (Weisman Institute (Rishal et al, 2013)) or ImageJ with NeuronJ plugin programs (ImageJ plugin; NIH). All neurons where axonal arbors could be traced by the software were assessed ( $\geq 75$ neurons per group/per experiment).

Fluorescence Recovery after Photobleaching (FRAP) - FRAP analyses was performed with minor modifications (Vuppalanchi et al., 2010). DRG neurons were transfected with GFP ${ }^{\text {MYR }} 3^{\prime}$ prenyl-Cdc42 or $\mathrm{GFP}^{\mathrm{MYR}} 3^{\prime}$ palm-Cdc42 or GFP ${ }^{\mathrm{MYR}} 3^{\prime} \gamma$-actin as a negative control. Cells were maintained at $37^{\circ} \mathrm{C}, 5 \% \mathrm{CO}_{2}$ during imaging sequences. The $488 \mathrm{~nm}$ laser line on Leica SP8X confocal microscope was used to bleach GFP signal (Argon laser at $70 \%$ power, pulsed every $0.82 \mathrm{sec}$ for 80 frames). Pinhole was set to 3 Airy units to ensure full thickness bleaching and acquisition (63 X/1.4 NA oil immersion objective) (Yudin et al, 2008). Prior to photobleaching, neurons were imaged every $60 \mathrm{sec}$ for $2 \mathrm{~min}$ to acquire baseline fluorescence in the region of interest (ROI; $15 \%$ laser power, $498-530 \mathrm{~nm}$ for GFP). The same excitation and emission parameters were used to assess recovery over $15 \mathrm{~min}$ post-bleach with images acquired 
SJ Lee et al.

Selective axonal localization of Cdc42 mRNA isoforms

every 30 secs. To determine if fluorescence recovery in axons due to translation, DRG cultures were treated with $100 \mu \mathrm{m}$ anisomycin (Sigma) for 30 min prior to photobleaching.

Fluorescent intensities in the bleached regions of interest (ROI) were calculated by the Leica LASX software. For normalizing across experiments, fluorescence intensity value at $t=0$ min postbleach from each image sequence was set as $0 \%$. The percentage of fluorescence recovery at each time point after photobleaching was calculated by normalizing relative to the pre-bleach fluorescence intensity for each image sequence was set at $100 \%$.

Analysis of RNA-Seq data - Raw FASTQ files of GSE51572, GSE66230, and GSE67828 were downloaded from NCBI GEO database and adaptor sequences were trimmed as necessary (Briese et al, 2016; Minis et al, 2014; Taliaferro et al, 2016). Unpublished axonal RNA-seq data from adult C57BI/6 mouse DRGs were similarly analyzed using a standard analysis pipeline (https://github.com/icnn/RNAseqPIPELINE.git). Briefly, reads were then aligned to mm10 genome using STAR with default parameters. Mapped reads for mRNAs were counted by HTSeq and then normalized by trimmed mean of M values using EdgeR. Normalized counts were used to quantify levels of $C d c 42$ splice variants in axons, neurites or cell bodies.

Statistical analyses - All experiments were performed in triplicate and each experiment was repeated at least 3 separate times and are reported as mean \pm standard deviation (SD) or standard error of the mean (SEM) as indicated in the figure legends. Student's t-test or one-way ANOVA with pairwise comparisons and Tukey post-hoc was used to determine significance differences between groups. GraphPad Prism 5 software was used for all statistical analyses.

ACKNOWLEDGEMENTS: This work was supported by grants from NIH (R01-NS041596 and R01NS089633 to JLT; P30-NS062691 to GC; and, R15-CA165202 to QL), the Dr. Miriam and Sheldon G. Adelson Medical Research Foundation (to JLT and GC), the Harriet and John Wooten Foundation for Alzheimer's Disease Research (to QL), and ASPIRE award from the University of South Carolina Office of 
SJ Lee et al.

Selective axonal localization of Cdc42 mRNA isoforms

Research (to SIL). JLT is the incumbent SmartState Chair in Childhood Neurotherapeutics at the University of South Carolina.

AUTHOR CONTRIBUTIONS: SJL, ANK, and JLT designed the study; SJL, ANK, RK, PP, PKS, KDL and CRM performed the experiments and analyzed the results. RK and GC provided supervision. QL provided critical reagents and advice. SJL and JLT wrote the article with inputs from ANK, QL, RK and GC.

CONFLICT OF INTEREST: The authors declare that they have no conflict of interest. 
SJ Lee et al.

Selective axonal localization of Cdc42 mRNA isoforms

\section{REFERENCES}

Aakalu G, Smith WB, Nguyen N, Jiang C, Schuman EM (2001) Dynamic visualization of local protein synthesis in hippocampal neurons. Neuron 30: 489-502.

Akins MR, Berk-Rauch HE, Kwan KY, Mitchell ME, Shepard KA, Korsak LI, Stackpole EE, Warner-Schmidt JL, Sestan N, Cameron HA, Fallon JR (2017) Axonal ribosomes and mRNAs associate with fragile $X$ granules in adult rodent and human brains. Hum Mol Genet 26: 192-209

An JJ, Gharami K, Liao GY, Woo NH, Lau AG, Vanevski F, Torre ER, Jones KR, Feng Y, Lu B, Xu B (2008) Distinct role of long 3' UTR BDNF mRNA in spine morphology and synaptic plasticity in hippocampal neurons. Cell 134: 175-187

Andreassi C, Riccio A (2009) To localize or not to localize: mRNA fate is in 3'UTR ends. Trends Cell Biol 19: 465-474

Banzai Y, Miki H, Yamaguchi H, Takenawa T (2000) Essential role of neural Wiskott-Aldrich syndrome protein in neurite extension in PC12 cells and rat hippocampal primary culture cells. J Biol Chem 275: 11987-11992

Ben-Yaakov K, Dagan S, Segal-Ruder Y, Shalem O, Vuppalanchi D, Willis DE, Yudin D, Rishal I, Blesch A, Pilpel Y, Twiss JL, Fainzilber M (2012) Axonal Transcription Factors Signal Retrogradely In Lesioned Peripheral Nerve. EMBO J 31: 1350-1363

Boulter E, Garcia-Mata R, Guilluy C, Dubash A, Rossi G, Brennwald PJ, Burridge K (2010) Regulation of Rho GTPase crosstalk, degradation and activity by RhoGDI1. Nat Cell Biol 12: 477-483

Briese M, Saal L, Appenzeller S, Moradi M, Baluapuri A, Sendtner M (2016) Whole transcriptome profiling reveals the RNA content of motor axons. Nucleic Acids Res 44: e33

Brittis PA, Lu Q, Flanagan JG (2002) Axonal protein synthesis provides a mechanism for localized regulation at an intermediate target. Cell 110: 223-235

Chandran V, Coppola G, Nawabi H, Omura T, Versano R, Huebner EA, Zhang A, Costigan M, Yekkirala A, Barrett L, Blesch A, Michaelevski I, Davis-Turak J, Gao F, Langfelder P, Horvath S, He Z, Benowitz L, Fainzilber M, Tuszynski M, Woolf CJ, Geschwind DH (2016) A Systems-Level Analysis of the Peripheral Nerve Intrinsic Axonal Growth Program. Neuron 89: 956-970

Chen C, Wirth A, Ponimaskin E (2012) Cdc42: an important regulator of neuronal morphology. Int J Biochem Cell Biol 44: 447-451

Da Silva JS, Medina M, Zuliani C, Di Nardo A, Witke W, Dotti CG (2003) RhoA/ROCK regulation of neuritogenesis via profilin Ila-mediated control of actin stability. J Cell Biol 162: 1267-1279

Emanuelsson O, Brunak S, von Heijne G, Nielsen H (2007) Locating proteins in the cell using TargetP, SignalP and related tools. Nat Protoc 2: 953-971

Estrada-Bernal A, Sanford SD, Sosa LJ, Simon GC, Hansen KC, Pfenninger KH (2012) Functional complexity of the axonal growth cone: a proteomic analysis. PLoS One 7: e31858

Etienne-Manneville S, Hall A (2002) Rho GTPases in cell biology. Nature 420: 629-635

Gomes C, Merianda TT, Lee SJ, Yoo S, Twiss JL (2014) Molecular determinants of the axonal mRNA transcriptome. Dev Neurobiol 74: 218-232 
SJ Lee et al.

Selective axonal localization of Cdc42 mRNA isoforms

Hall A, Lalli G (2010) Rho and Ras GTPases in axon growth, guidance, and branching. Cold Spring Harb Perspect Biol 2: a001818

Hamid FM, Makeyev EV (2014) Regulation of mRNA abundance by polypyrimidine tract-binding proteincontrolled alternate 5' splice site choice. PLoS Genet 10: e1004771

Jalink K, van Corven EJ, Hengeveld T, Morii N, Narumiya S, Moolenaar WH (1994) Inhibition of lysophosphatidate- and thrombin-induced neurite retraction and neuronal cell rounding by ADP ribosylation of the small GTP-binding protein Rho. J Cell Biol 126: 801-810

Jin LQ, Pennise CR, Rodemer W, Jahn KS, Selzer ME (2016) Protein synthetic machinery and mRNA in regenerating tips of spinal cord axons in lamprey. J Comp Neurol 524: 3614-3640

Kalinski AL, Sachdeva R, Gomes C, Lee SJ, Shah Z, Houle JD, Twiss JL (2015) mRNAs and Protein Synthetic Machinery Localize into Regenerating Spinal Cord Axons When They Are Provided a Substrate That Supports Growth. J Neurosci 35: 10357-10370

Kang R, Wan J, Arstikaitis P, Takahashi H, Huang K, Bailey AO, Thompson JX, Roth AF, Drisdel RC, Mastro R, Green WN, Yates JR, 3rd, Davis NG, El-Husseini A (2008) Neural palmitoyl-proteomics reveals dynamic synaptic palmitoylation. Nature 456: 904-909

Kar AN, Lee S, Twiss J (2018) Expanding Axonal Transcriptome Brings New Functions for Axonally Synthesized Proteins in Health and Disease. The Neuroscientist 24: 111-129

Le Hir H, Sauliere J, Wang Z (2016) The exon junction complex as a node of post-transcriptional networks. Nat Rev Mol Cell Biol 17: 41-54

Li H, Kuwajima T, Oakley D, Nikulina E, Hou J, Yang WS, Lowry ER, Lamas NJ, Amoroso MW, Croft GF, Hosur R, Wichterle H, Sebti S, Filbin MT, Stockwell B, Henderson CE (2016) Protein Prenylation Constitutes an Endogenous Brake on Axonal Growth. Cell Reports 16: 545-558

Luo L (2000) Rho GTPases in neuronal morphogenesis. Nat Rev Neurosci 1: 173-180

Luo L, Liao YJ, Jan LY, Jan YN (1994) Distinct morphogenetic functions of similar small GTPases: Drosophila Drac1 is involved in axonal outgrowth and myoblast fusion. Genes Dev 8: 1787-1802

Makeyev EV, Zhang J, Carrasco MA, Maniatis T (2007) The MicroRNA miR-124 promotes neuronal differentiation by triggering brain-specific alternative pre-mRNA splicing. Mol Cell 27: 435-448

Matsuura R, Tanaka H, Go MJ (2004) Distinct functions of Rac1 and Cdc42 during axon guidance and growth cone morphogenesis in Drosophila. Eur J Neurosci 19: 21-31

Merianda TT, Coleman J, Kim HH, Kumar Sahoo P, Gomes C, Brito-Vargas P, Rauvala H, Blesch A, Yoo S, Twiss JL (2015) Axonal amphoterin mRNA is regulated by translational control and enhances axon outgrowth. J Neurosci 35: 5693-5706

Merianda TT, Gomes C, Yoo S, Vuppalanchi D, Twiss JL (2013) Axonal localization of neuritin/CPG15 mRNA in neuronal populations through distinct 5' and 3' UTR elements. J Neurosci 33: 13735-13742

Ming GL, Wong ST, Henley J, Yuan XB, Song HJ, Spitzer NC, Poo MM (2002) Adaptation in the chemotactic guidance of nerve growth cones. Nature 417: 411-418

Minis A, Dahary D, Manor O, Leshkowitz D, Pilpel Y, Yaron A (2014) Subcellular transcriptomicsdissection of the mRNA composition in the axonal compartment of sensory neurons. Dev Neurobiol 74: 365-381 
SJ Lee et al.

Selective axonal localization of Cdc42 mRNA isoforms

Moor AE, Golan M, Massasa EE, Lemze D, Weizman T, Shenhav R, Baydatch S, Mizrahi O, Winkler R, Golani O, Stern-Ginossar N, Itzkovitz S (2017) Global mRNA polarization regulates translation efficiency in the intestinal epithelium. Science 357: 1299-1303

Myers JP, Robles E, Ducharme-Smith A, Gomez TM (2012) Focal adhesion kinase modulates Cdc42 activity downstream of positive and negative axon guidance cues. J Cell Sci 125: 2918-2929

Nicole S, White PS, Topaloglu H, Beigthon P, Salih M, Hentati F, Fontaine B (1999) The human CDC42 gene: genomic organization, evidence for the existence of a putative pseudogene and exclusion as a SJS1 candidate gene. Hum Genet 105: 98-103

Nishimura A, Linder ME (2013) Identification of a novel prenyl and palmitoyl modification at the CaaX motif of Cdc42 that regulates RhoGDI binding. Mol Cell Biol 33: 1417-1429

Nishimura T, Yamaguchi T, Kato K, Yoshizawa M, Nabeshima Y, Ohno S, Hoshino M, Kaibuchi K (2005) PAR-6-PAR-3 mediates Cdc42-induced Rac activation through the Rac GEFs STEF/Tiam1. Nat Cell Biol 7: 270-277

Perry RB, Doron-Mandel E, lavnilovitch E, Rishal I, Dagan SY, Tsoory M, Coppola G, McDonald MK, Gomes C, Geschwind DH, Twiss JL, Yaron A, Fainzilber M (2012) Subcellular knockout of importin beta1 perturbs axonal retrograde signaling. Neuron 75: 294-305

Piper M, Anderson R, Dwivedy A, Weinl C, van Horck F, Leung KM, Cogill E, Holt C (2006) Signaling mechanisms underlying Slit2-induced collapse of Xenopus retinal growth cones. Neuron 49: 215-228

Rangaraju V, Tom Dieck S, Schuman EM (2017) Local translation in neuronal compartments: how local is local? EMBO Reports 18: 693-711

Rishal I, Golani O, Rajman M, Costa B, Ben-Yaakov K, Schoenmann Z, Yaron A, Basri R, Fainzilber M, Galun M (2013) WIS-NeuroMath enables versatile high throughput analyses of neuronal processes. Dev Neurobiol 73: 247-256

Roberts PJ, Mitin N, Keller PJ, Chenette EJ, Madigan JP, Currin RO, Cox AD, Wilson O, Kirschmeier P, Der CJ (2008) Rho Family GTPase modification and dependence on CAAX motif-signaled posttranslational modification. J Biol Chem 283: 25150-25163

Sahoo PK, Smith DS, Perrone-Bizzozero N, Twiss JL (2018) Axonal mRNA transport and translation at a glance. J Cell Sci 131 pii: jcs196808

Schwamborn JC, Puschel AW (2004) The sequential activity of the GTPases Rap1B and Cdc42 determines neuronal polarity. Nat Neurosci 7: 923-929

Shestakova EA, Singer RH, Condeelis J (2001) The physiological significance of beta -actin mRNA localization in determining cell polarity and directional motility. Proc Natl Acad Sci USA 98: 7045-7050

Shigeoka T, Jung H, Jung J, Turner-Bridger B, Ohk J, Lin JQ, Amieux PS, Holt CE (2016) Dynamic Axonal Translation in Developing and Mature Visual Circuits. Cell 166: 181-192

Taliaferro JM, Vidaki M, Oliveira R, Olson S, Zhan L, Saxena T, Wang ET, Graveley BR, Gertler FB, Swanson MS, Burge CB (2016) Distal Alternative Last Exons Localize mRNAs to Neural Projections. Mol Cell 61: 821-833

Terenzio M, Schiavo G, Fainzilber M (2017) Compartmentalized Signaling in Neurons: From Cell Biology to Neuroscience. Neuron 96: 667-679 
SJ Lee et al.

Selective axonal localization of Cdc42 mRNA isoforms

Walker BA, Hengst U, Kim HJ, Jeon NL, Schmidt EF, Heintz N, Milner TA, Jaffrey SR (2012a)

Reprogramming axonal behavior by axon-specific viral transduction. Gene Ther 19: 947-955

Walker BA, Ji SJ, Jaffrey SR (2012b) Intra-axonal translation of RhoA promotes axon growth inhibition by CSPG. J Neurosci 32: 14442-14447

Willis DE, van Niekerk EA, Sasaki Y, Mesngon M, Merianda TT, Williams GG, Kendall M, Smith DS, Bassell GJ, Twiss JL (2007) Extracellular stimuli specifically regulate localized levels of individual neuronal mRNAs. J Cell Biol 178: 965-980

Willis DE, Xu M, Donnelly CJ, Tep C, Kendall M, Erenstheyn M, English AW, Schanen NC, Kirn-Safran CB, Yoon SO, Bassell GJ, Twiss JL (2011) Axonal Localization of transgene mRNA in mature PNS and CNS neurons. J Neurosci 31: 14481-14487

Wirth A, Chen-Wacker C, Wu YW, Gorinski N, Filippov MA, Pandey G, Ponimaskin E (2013) Dual lipidation of the brain-specific Cdc42 isoform regulates its functional properties. Biochem J 456: 311-322

Wong K, Ren XR, Huang YZ, Xie Y, Liu G, Saito H, Tang H, Wen L, Brady-Kalnay SM, Mei L, Wu JY, Xiong WC, Rao Y (2001) Signal transduction in neuronal migration: roles of GTPase activating proteins and the small GTPase Cdc42 in the Slit-Robo pathway. Cell 107: 209-221

Wu KY, Hengst U, Cox LJ, Macosko EZ, Jeromin A, Urquhart ER, Jaffrey SR (2005) Local translation of RhoA regulates growth cone collapse. Nature 436: 1020-1024

Yap K, Xiao Y, Friedman BA, Je HS, Makeyev EV (2016) Polarizing the Neuron through Sustained Coexpression of Alternatively Spliced Isoforms. Cell Rep 15: 1316-1328

Yoo S, Kim HH, Kim P, Donnelly CJ, Kalinski AL, Vuppalanchi D, Park M, Lee SJ, Merianda TT, PerroneBizzozero NI, Twiss JL (2013) A HuD-ZBP1 ribonucleoprotein complex localizes GAP-43 mRNA into axons through its 3' untranslated region AU-rich regulatory element. J Neurochem 126: 792-804

Yuan XB, Jin M, Xu X, Song YQ, Wu CP, Poo MM, Duan S (2003) Signalling and crosstalk of Rho GTPases in mediating axon guidance. Nat Cell Biol 5: 38-45

Yudin D, Hanz S, Yoo S, lavnilovitch E, Willis D, Gradus T, Vuppalanchi D, Segal-Ruder Y, Ben-Yaakov K, Hieda M, Yoneda Y, Twiss JL, Fainzilber M (2008) Localized regulation of axonal RanGTPase controls retrograde injury signaling in peripheral nerve. Neuron 59: 241-252

Zheng JQ, Kelly TK, Chang B, Ryazantsev S, Rajasekaran AK, Martin KC, Twiss JL (2001) A functional role for intra-axonal protein synthesis during axonal regeneration from adult sensory neurons. J Neurosci 21: 9291-9303 
SJ Lee et al.

Selective axonal localization of Cdc42 mRNA isoforms

\section{FIGURE LEGENDS}

Figure 1: Alternatively spliced Cdc42 isoform mRNAs differentially localize to axons of sensory neurons.

A, Schematic for alternative splicing for $C d c 42$ gene products. The two $C d c 42$ mRNAs have distinct 3'UTRs from alternative use of exons 6 or 7 . These two mRNAs encode proteins with different C-termini. The protein coding portions of $C d c 42$ exons 6 and 7 are shown in darkly shaded green and orange, respectively; the 3'UTR encoding portions of exons 6 and 7 are shown in lightly shaded green and orange, respectively.

B, Representative ethidium bromide stained agarose gel of RT-PCR for RNA isolated from axonal and cell body compartments of dissociated DRG neurons is shown.

C, RT-ddPCR for prenyl-Cdc42 and palm-Cdc42 mRNAs is shown as mean copy number \pm SEM; Hmgb1 was used for input RNA normalization ( $\mathrm{N}=3$ biological replicates).

D, Representative images of DRG neuron cultures for CDC42 isoform mRNA FISH, neurofilament (NF) immunofluorescence, and corresponding DIC are shown [Scale bars $=10 \mu \mathrm{m}$ ].

E-F, Quantification of FISH signal intensities are shown as mean pixel intensity \pm SEM ( $n \geq 60$ neurons from 3 independent transfections; ${ }^{* *} \mathrm{P}<0.01$ by one-way ANOVA with pair-wise comparison and Tukey post-hoc tests).

Figure 2: prenyl-Cdc42 mRNA isoform 3'UTR drives axonal mRNA localization and translation.

A, Representative FISH/IF for GFP mRNA and NF protein in DRG neurons transfected with GFPMYR reporter containing 3'UTRs of prenyl-Cdc42 or palm-Cdc42 mRNAs (GFP ${ }^{\text {MYR }}-3$ 'prenyl-cdc42 and $\mathrm{GFP}^{\mathrm{MYR}} 3^{\prime}$ palm-cdc42, respectively) are shown [Scale bars $=10 \mu \mathrm{m}$ ]. 
SJ Lee et al.

Selective axonal localization of Cdc42 mRNA isoforms

B-C, Quantifications of GFP mRNA signals from FISH for cell bodies (B) and axons (C) are shown as mean pixel intensity $\pm \mathrm{SEM} . \mathrm{GFP}^{\mathrm{MYR}} 3^{\prime} \gamma$-actin was used as a negative control ( $\mathrm{N} \geq 45$ neurons in 3 transfections; $* * * \mathrm{p} \leq 0.001$ by one-way ANOVA with pair-wise comparison and Tukey post-hoc).

D-E, FRAP analyses for distal axons of DRG neurons expressing indicated GFP ${ }^{\text {MYR }}$ reporter constructs as in A are shown as mean $\%$ normalized average recovery \pm SEM (pre-bleach $=100 \%$ and post-bleach $=0 \%$ ). The GFP ${ }^{\text {MYR }} 3^{\prime}$ prenyl-Cdc42 shows significantly greater recovery of fluorescence in axons than $\mathrm{GFP}^{\mathrm{MYR}} 3^{\prime}$ palm-Cdc42 and GFP ${ }^{\mathrm{MYR}} 3^{\prime} \gamma$-actin. Note that translation inhibition prior to photobleaching shows that post-bleach signals of GFP ${ }^{\mathrm{MYR}} 3^{\prime}$ prenyl-Cdc42 requires protein synthesis ( $\mathrm{N} \geq 15$ neurons tested over 3 culture preparations; ${ }^{* * * *} \mathrm{P}<0.001$ by two-way ANOVA with pair-wise comparison and Tukey post-hoc tests).

\section{Figure 3: prenyl-Cdc42 isoform depletion decreases axon growth.}

A, Locations of siRNAs targeting both Cdc42 mRNAs, prenyl-Cdc42 mRNA, and palm-Cdc42 mRNA are shown. Two closely spaced siRNAs were designed to target prenyl-Cdc42 and palm-Cdc42 mRNAs (designated as ' 1 ' and ' 2 ' in panels B-C and E).

B-C, Cdc42 mRNA levels were assessed by RT-ddPCR using primers selective for the prenyl-Cdc42 (B) and palm-Cdc42 (C) mRNA. Relative mRNA levels were calculated after normalization with Hmgb1 mRNA and are shown as mean fold-change relative to control siRNA (siCon) $\pm \mathrm{SEM}\left(\mathrm{N}=3 ;{ }^{*} \mathrm{P}<0.05, * * \mathrm{P}<\right.$ 0.01 and $* * * P<0.005$ by one-way ANOVA with pair-wise comparison and Tukey post-hoc tests). D, Representative images of NF for rat DRG neurons transfected with siRNAs from $A$ at $48 \mathrm{~h}$ posttransfection [Scale bar $=100 \mu \mathrm{m}]$.

E, Mean total axon length/neuron \pm SEM is shown for neurons transfected with siRNAs as in $A$ ( $N \geq 90$ neurons tested over 3 culture preparations; ${ }^{*} \mathrm{P}<0.05$ and ${ }^{* *} \mathrm{P}<0.005$ by one-way ANOVA with pairwise comparison and Tukey post-hoc tests.) 
SJ Lee et al.

Selective axonal localization of Cdc42 mRNA isoforms

\section{Figure 4: Axonal prenyl-Cdc42 mRNA rescues axon growth reduction by siRNA.}

A, Schematic of the cDNAs expressed for siRNA resistant rescue experiments shown in panel B-D is shown.

B, Representative NF immunofluorescent images of rat DRG neurons transfected with control or panCdc42 siRNAs plus si-resistant expression constructs from A at $96 \mathrm{hrs}$ post-transfection [Scale bar $=20$ $\mu \mathrm{m}]$.

C, Axon length/neuron for DRG neurons transfected as in A-B is shown as mean fold-change \pm SEM relative to siCon + GFP transfection ( $N \geq 150$ neurons over 3 replicates; $* * P<0.005$ by one-way ANOVA with pair-wise comparison and Tukey post-hoc tests).

D, Axon branching for DRG neurons transfected as in A-B is shown by mean branch points/ $\mu \mathrm{m} \pm \mathrm{SEM}$ ( $\mathrm{N}$ $\geq 150$ neurons over 3 replicates; no significant changes by one-way ANOVA with pair-wise comparison and Tukey post-hoc tests).

Figure 5: C-terminal CaaX motif is needed for optimal axon growth by axonal prenyl-Cdc42 mRNA.

A, Schematic for si-resistant Cdc42 mRNA splice variants with mutations in CaaX and CCaX motifs is shown.

B, Axon length/neuron for DRG neurons transfected with control vs. pan-Cdc42 siRNAs plus the indicated mutant $\mathrm{CDC} 42$ isoforms is shown. Note that all mutants were targeted into axons using the 3'UTR from prenyl-Cdc42 mRNA. Values are shown as fold change relative to siCon + eGFP and error bars represent SEM ( $N \geq 120$ neurons over 3 transfections; $* \mathrm{P}<0.05$ and $* * * P<0.005$ by one-way ANOVA with pair-wise comparison and Tukey post-hoc).

C, Axon branching for DRG neurons transfected with pan-Cdc42 siRNAs as in B is shown as mean branch points/ $\mu \mathrm{m}$ axon length \pm SEM $\left(\mathrm{N} \geq 120\right.$ neurons over 3 replicate transfections; ${ }^{*} \mathrm{P}<0.05$ and $* * * \mathrm{P}<$ 0.005 by one-way ANOVA with pair-wise comparison and Tukey post-hoc). 
SJ Lee et al.

Selective axonal localization of Cdc42 mRNA isoforms

Figure 6: Axonal mRNA localization and prenylation is required for Cdc42 protein accumulation at the periphery of growth cone

A, Schematic of GFP-CDC42 expression constructs with mutated C-termini and indicated cell bodyrestricted (GFP) or axonally-localizing (prenyl-Cdc42) 3'UTRs.

B-I, Representative images for distal axon and growth cones are shown as maximum XYZ projection from deconvolved optical Z planes. GFP is shown in the upper row as the indicated spectral intensity images $(B, D, F$, and $H)$ and $N F$ is shown in red in the lower role $(C, E, G$, and $I)$ [Scale bar $=10 \mu \mathrm{m}$ ]. 
SJ Lee et al.

Selective axonal localization of Cdc42 mRNA isoforms

\section{EXPANDED VIEW FIGURE LEGENDS}

\section{Figure EV1: Normalized counts of prenyl-Cdc42 and palm-Cdc42 mRNAs from subcellular transcriptome datasets of different neuron types}

Raw data of published and unpublished subcellular RNA-seq datasets were analyzed to obtain normalized counts. Mean values \pm SEM of normalized counts for prenyl-Cdc42 and palm-Cdc42 mRNAs from biological replicates are plotted. Datasets were from cell body and axon-enriched transcriptomes of: A, embryonic DRG neurons (Minis et al, 2014); B, embryonic motor neurons (Briese et al, 2016); C, adult DRG neurons (unpublished data); and D, cell body-/neurite-enriched transcriptome of embryonic cortical neurons (Taliaferro et al, 2016).

\section{Figure EV2: Axonal localization of prenyl-Cdc42 does not require splicing}

A, Schematics of GFP-Cdc42 constructs designed to mimic pre-mRNA splicing differences between prenyl-Cdc42 and palm-Cdc42 mRNAs ('mini-genes') or mature mRNA ('cDNA'). B, Representative ethidium-stained agarose gel for RT-PCR to detect splice variants using primers outlined in A is shown. The two lanes of for the Cdc42 mini-genes show replicate transfections. Amplification with primers $1+$ 2 shows relatively equivalent expression across the transfections. Amplification with primers $3+4$ and 3 + 5 shows anticipated splice variants for mini-gene constructs. Control is untransfected DRGs. C-D, Quantification of GFP mRNA signals from FISH for cell bodies (C) and axons (D). GFP was used as a negative control. Error bars represent SEM ( $N \geq 30$ neurons from 3 biological replicates; ${ }^{* * *} \mathrm{p}<0.001,{ }^{*}$ $p<0.05$ by one-way ANOVA with pair-wise comparison and Tukey post-hoc). 
SJ Lee et al.

Selective axonal localization of Cdc42 mRNA isoforms

Table EV1: Alternatively spliced variants of Cdc42 are found from fishes to mammals

Sequence comparison along the phylogenetic tree revealed conservation of Cdc42 alternative splicing

from fishes to primates. Notice the last four amino acids of the C-termini of each protein products.

\begin{tabular}{|c|c|c|c|c|}
\hline Species (common name) & $\begin{array}{c}\text { NCBI Accession \# } \\
\text { prenyl-Cdc42 }\end{array}$ & $\begin{array}{c}\text { NCBI Accession \# } \\
\text { palm-Cdc42 }\end{array}$ & $\begin{array}{c}\text { CaaX motif } \\
\text { prenyl- } \\
\text { Cdc42 } \\
\end{array}$ & $\begin{array}{l}\text { CCaX motif } \\
\text { palm-Cdc42 }\end{array}$ \\
\hline Saccharomyces cerevisiae (yeast) & NM_001182116.1 & - & CAIL & - \\
\hline Caenorhabditis elegans (worm) & NM_063197.7 & - & CNIL & - \\
\hline Saccoglossus kowalevskii (worm) & NM_001168041.1 & - & CVLL & - \\
\hline Acanthaster planci (star fish) & XM_022244898.1 & - & CSLL & - \\
\hline Danio rerio (zebra fish) & NM_200632.2 & NM_001018120.2 & CVLL & $\mathrm{CCIF}$ \\
\hline Xenopus tropicalis (frog) & NM_001017070.3 & NM_001008026.1 & CRLL & CCIF \\
\hline Xenopus laevis (frog) & NM_001085899.1 & XM_018224258.1 & CMLL & CCIF \\
\hline Nanorana parkeri (frog) & XM_018568983.1 & XM_018568984.1 & CRLL & CCIF \\
\hline Callorhinchus milii (shark) & XM_007897764.1 & XM_007897763.1 & CVLL & CCIF \\
\hline Python bivittatus (snake) & XM_015889191.1 & XM_015889192.1 & CVLL & CCIF \\
\hline Alligator mississippiensis (alligator) & XM_014597185.2 & XM_014597186.2 & CVLL & CCIF \\
\hline Gallus gallus (chicken) & NM_205048.1 & XM_015296827.1 & CVLL & CCIF \\
\hline Chelonia mydas (turtle) & XM_007065922.1 & XM_007065923.1 & CVLL & CCIF \\
\hline Mus musculus (mouse) & NM_009861.3 & NM_001243769.1 & CVLL & CCIF \\
\hline Homo sapiens (human) & NM_001039802.1 & NM_044472.2 & CVLL & CCIF \\
\hline
\end{tabular}




\section{Figure 1}

A

Cdc42 gene structure

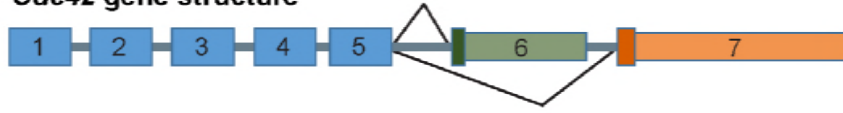

palm-Cdc42

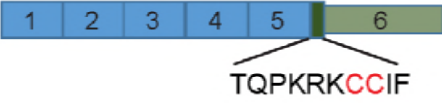

prenyl-Cdc42

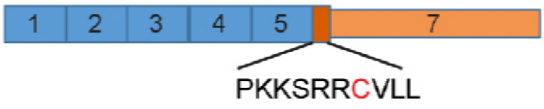

PKKSRRCVLL

D

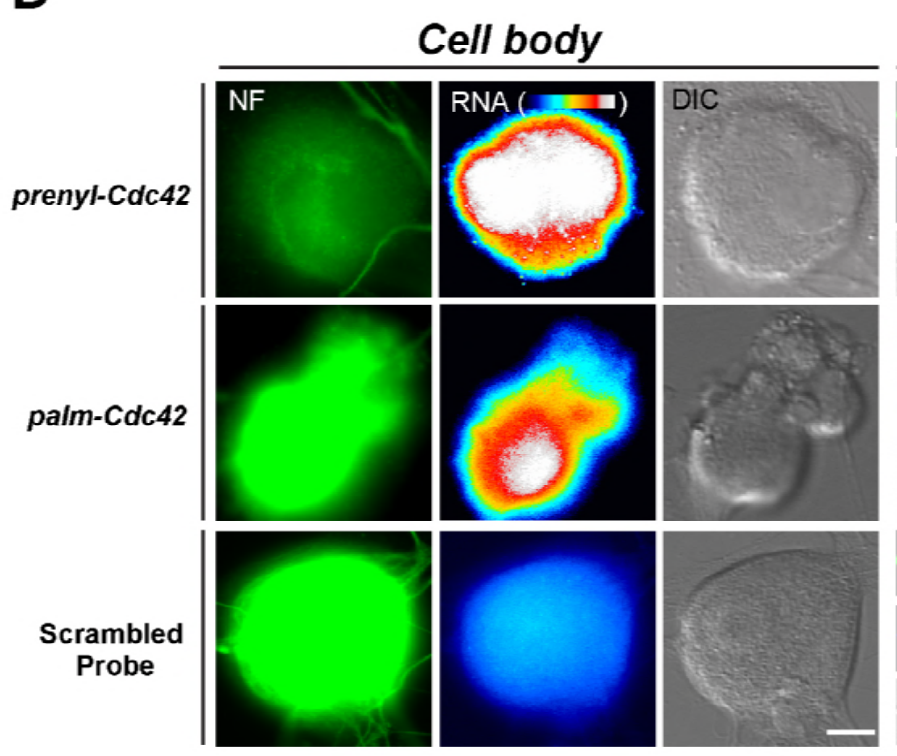

B

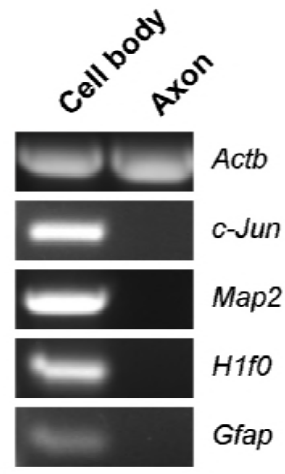

C

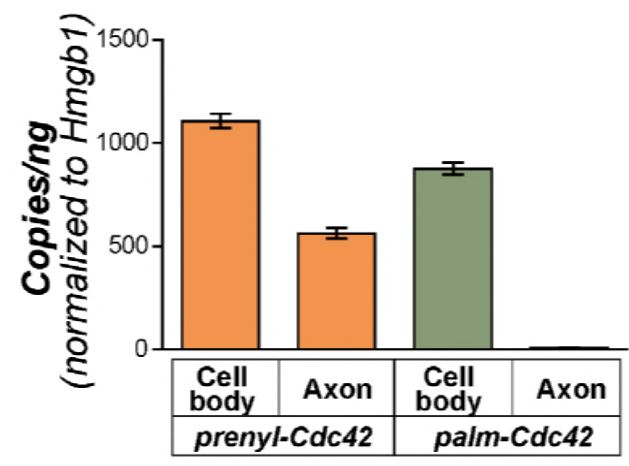

Axon

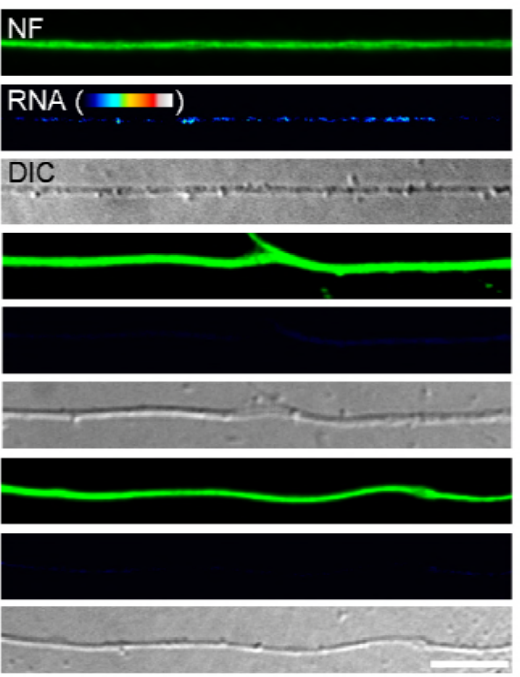

E

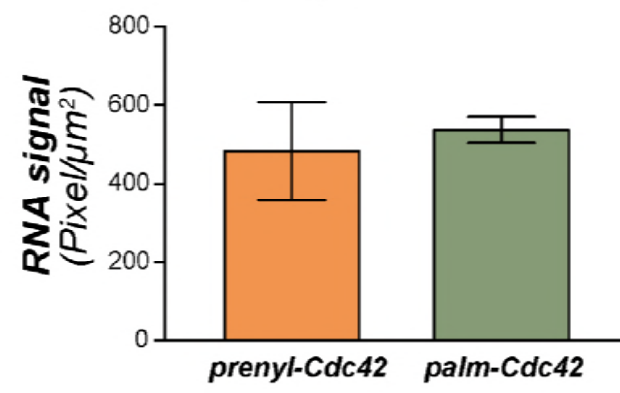

F

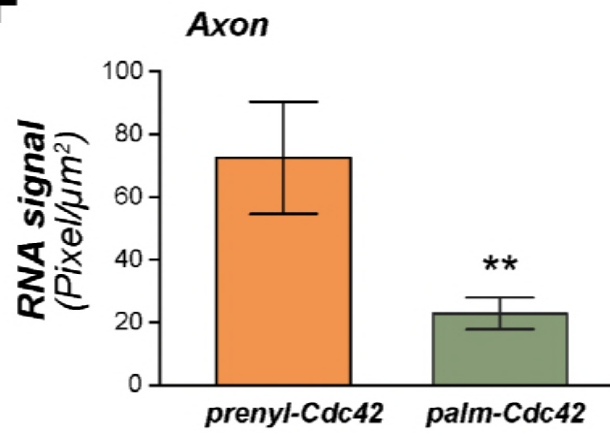


A

3'prenyl-cdc42

GFPMYR

3'palm-cdc42

Sense probe
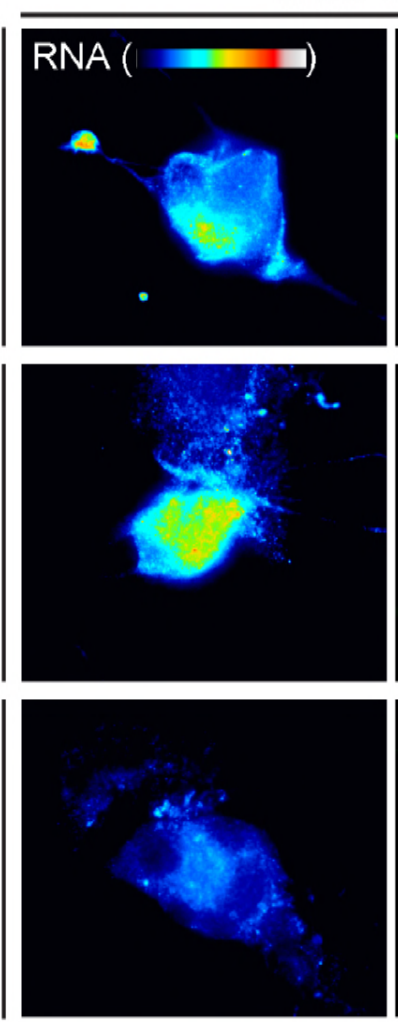

Cell body
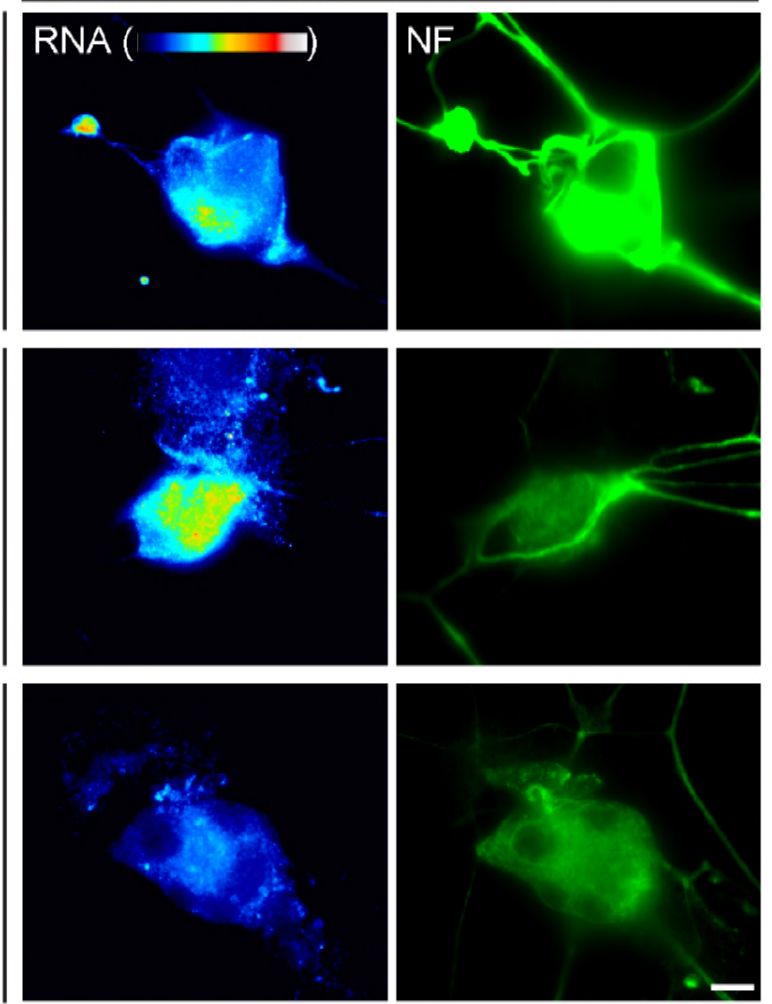

B

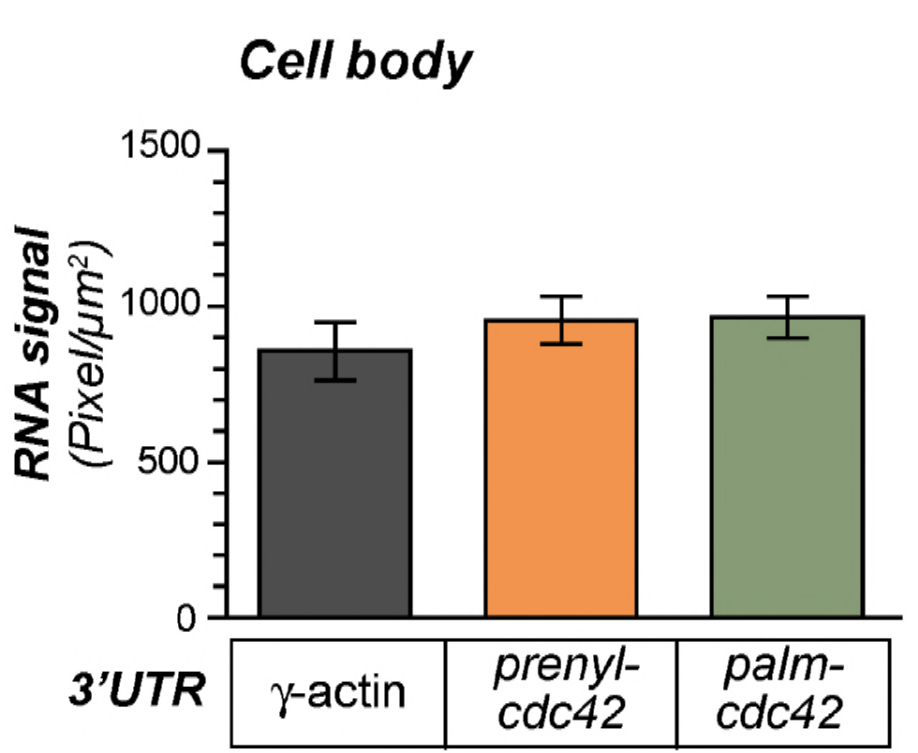

D

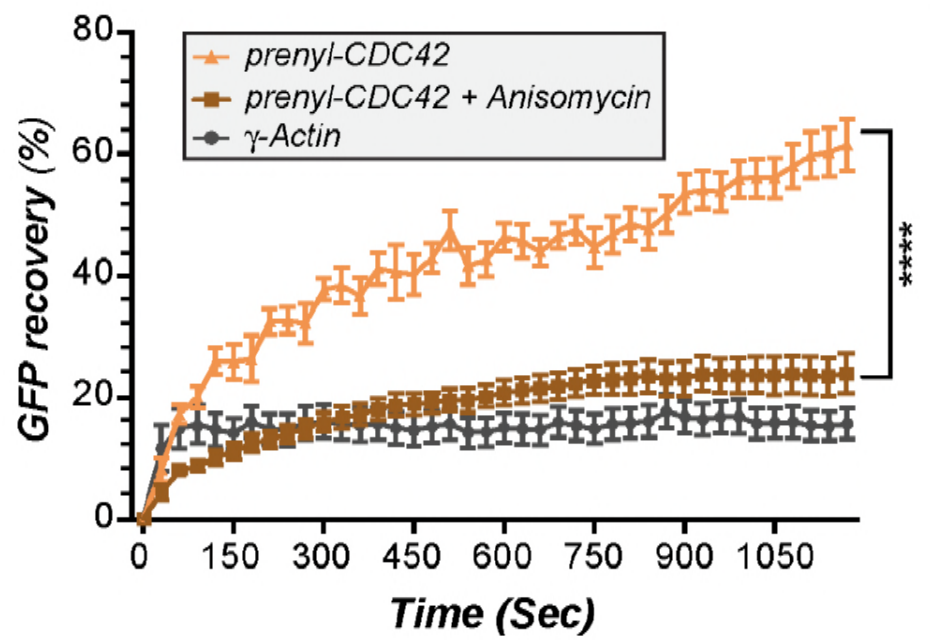

Axon
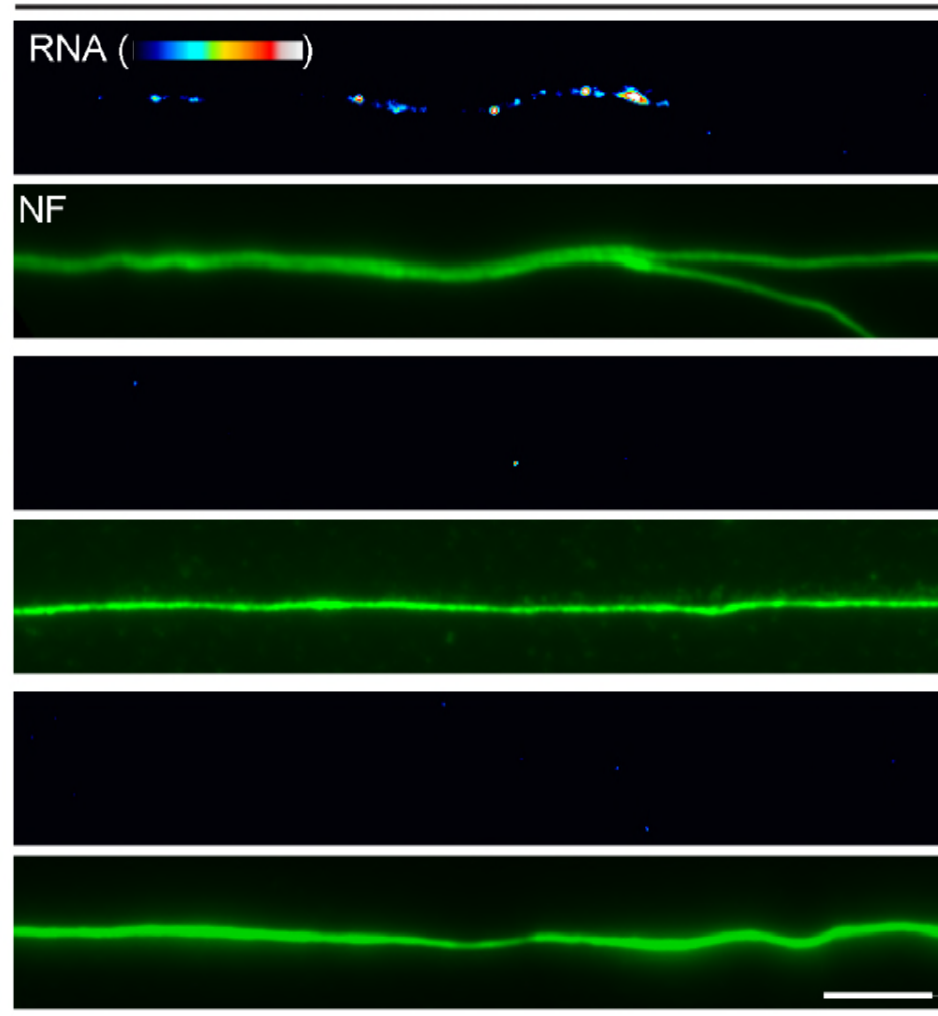

C

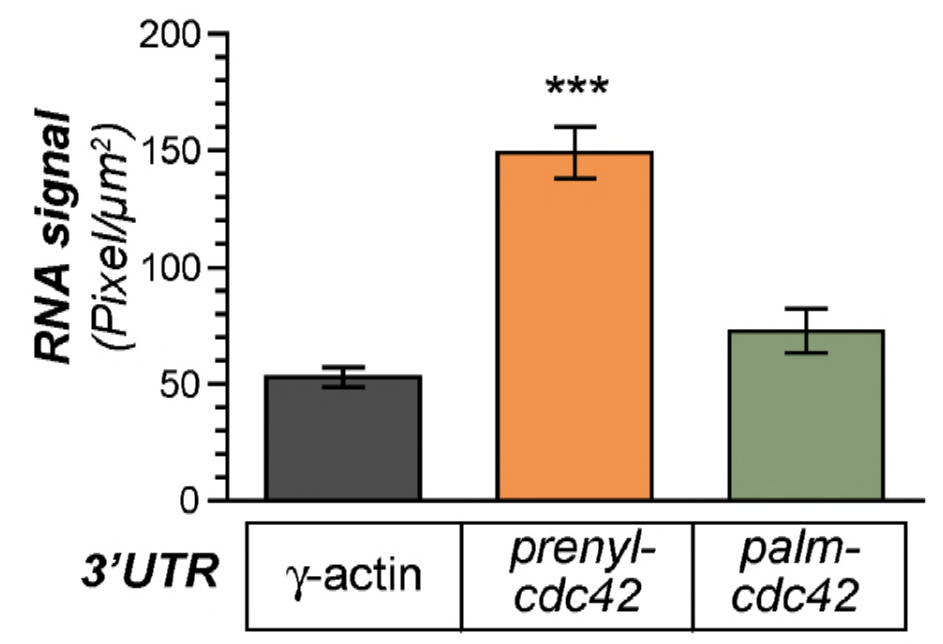

E

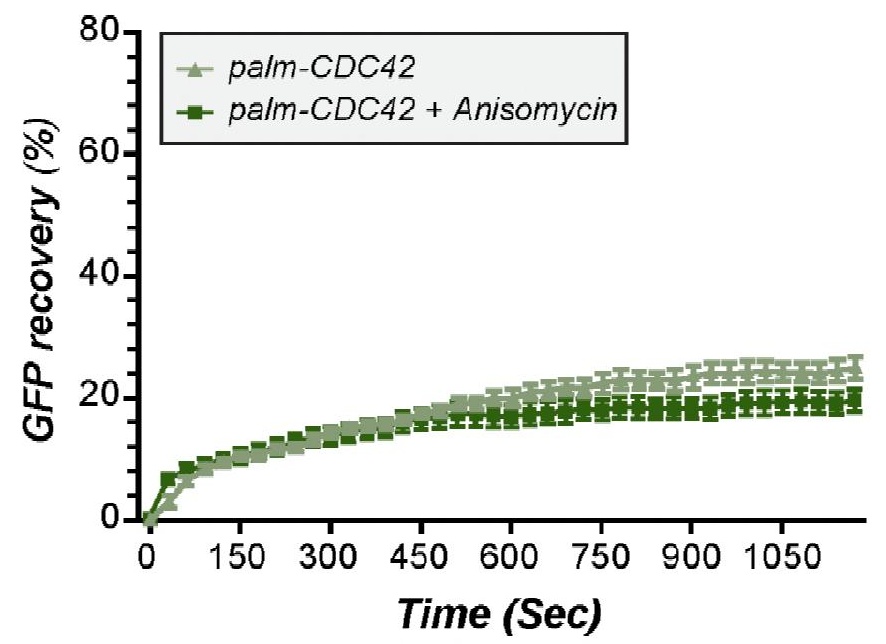




\section{Figure 3}

A

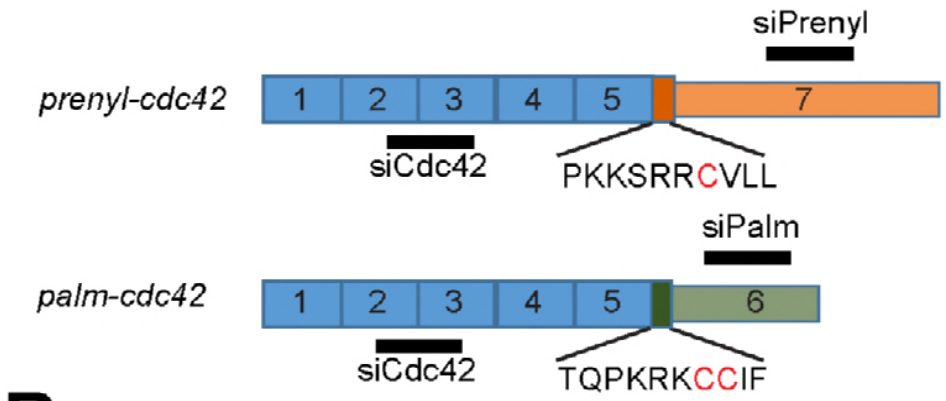

B

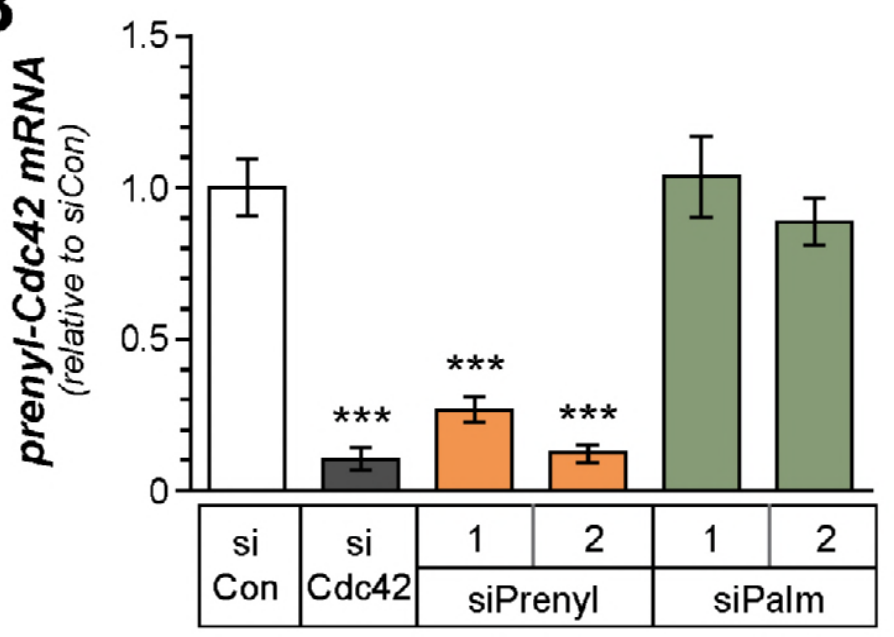

C

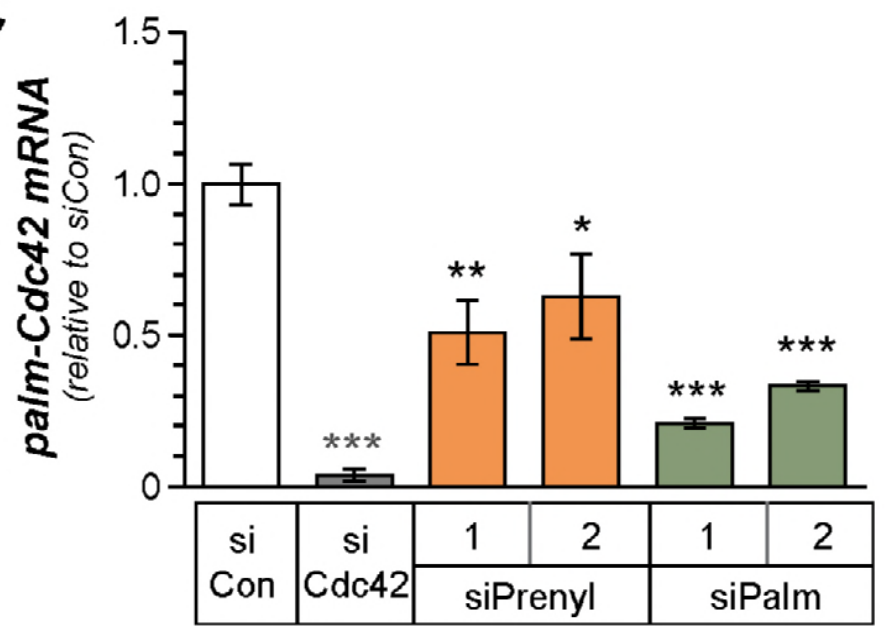

\section{D}

\section{sicon}

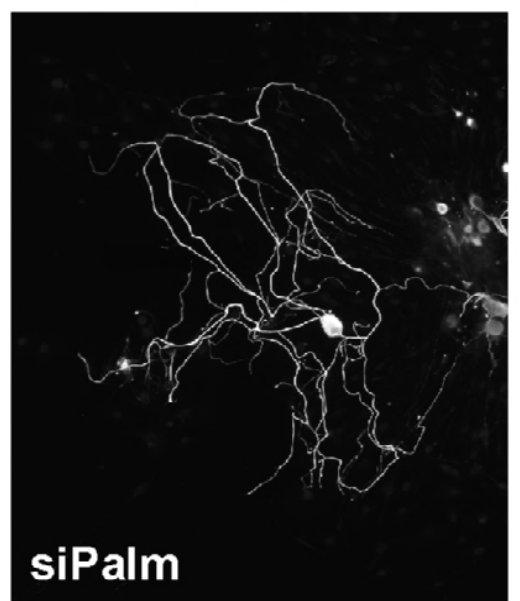

\section{siPrenyl}

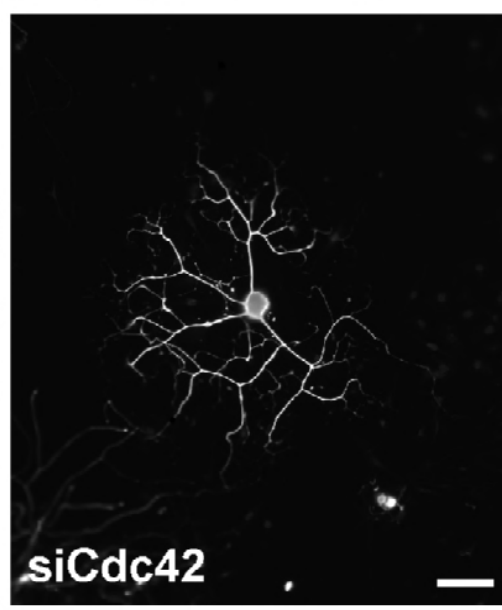

$\mathbf{E}$

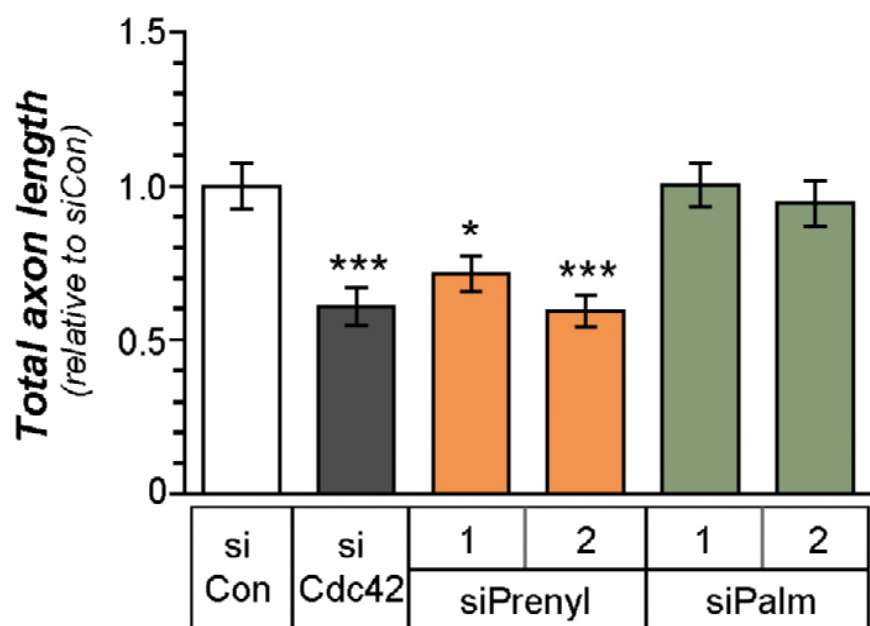




\section{Figure 4}

A

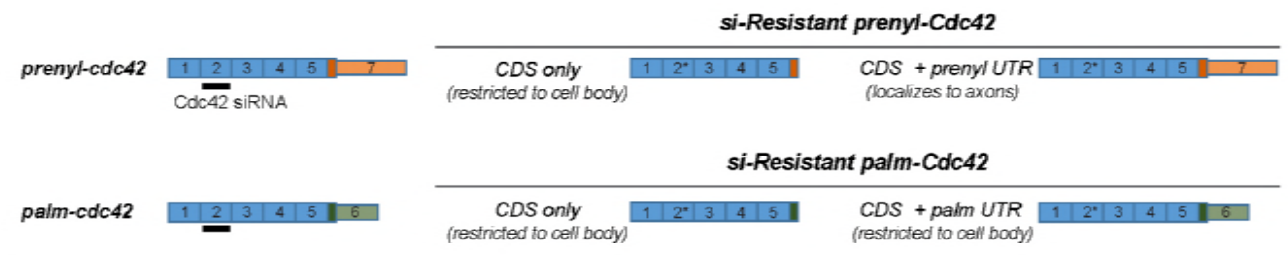

B
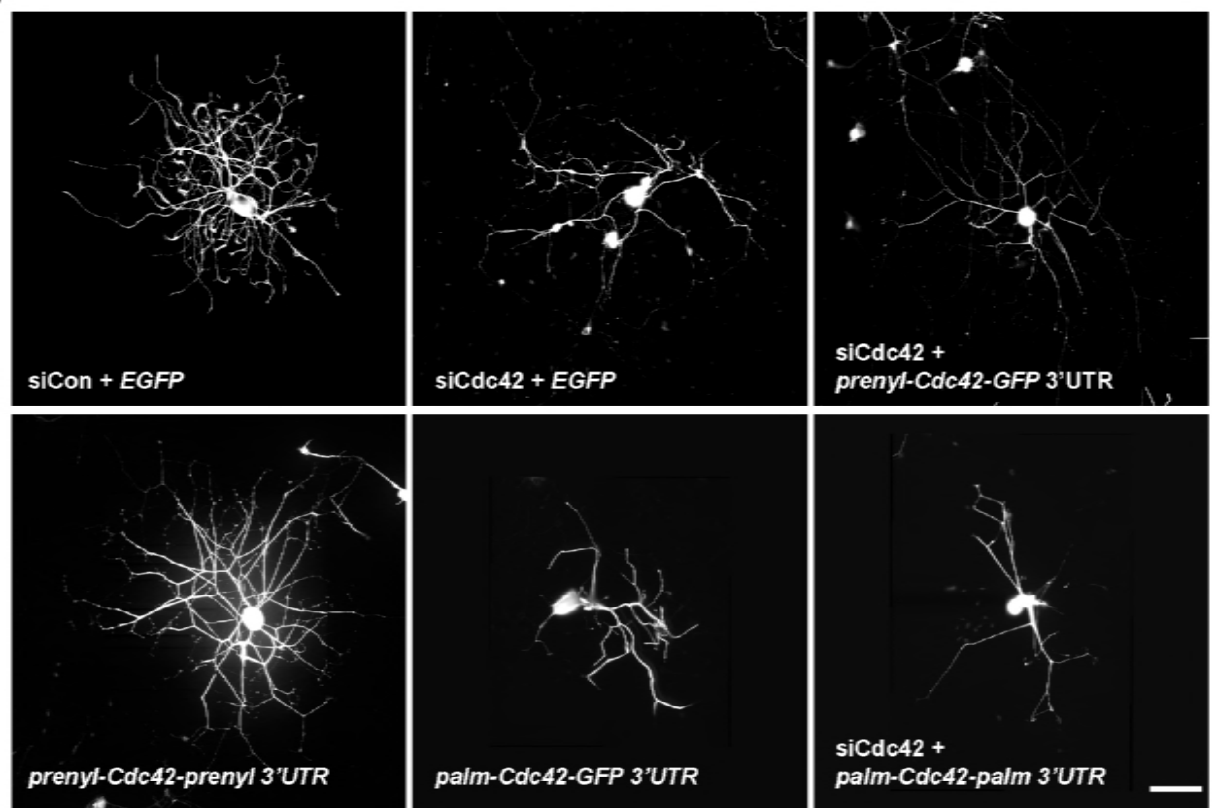

C
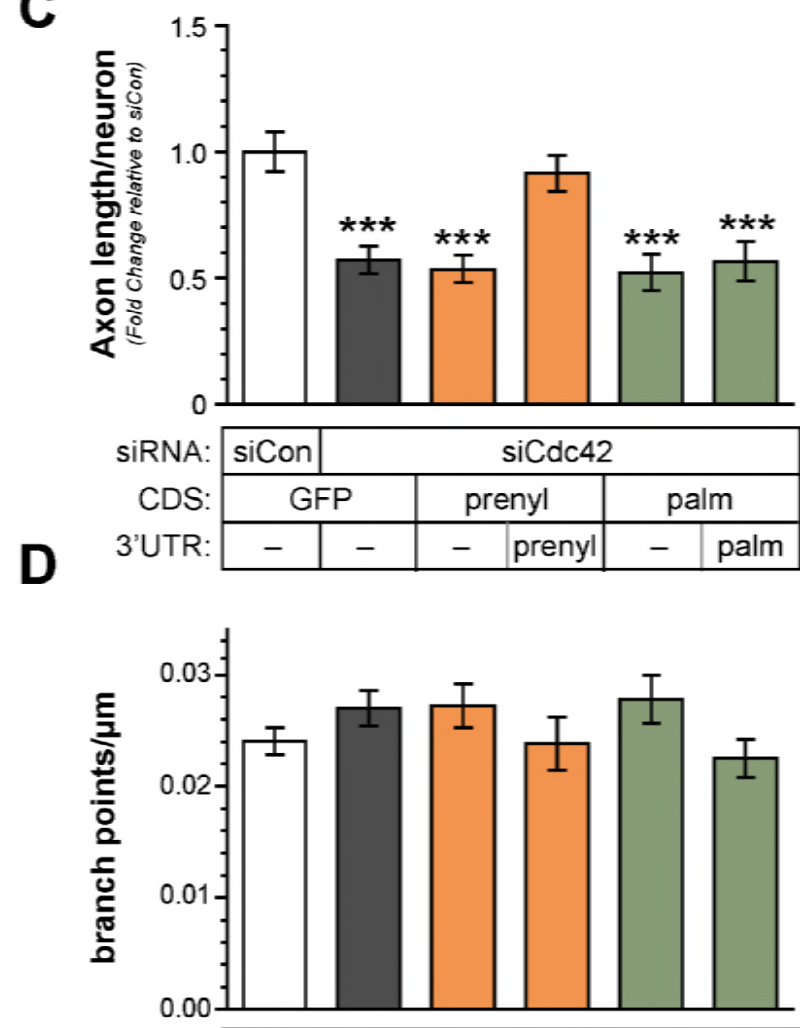

siCdc42 +

palm-Colc42-palm 3 UTR 


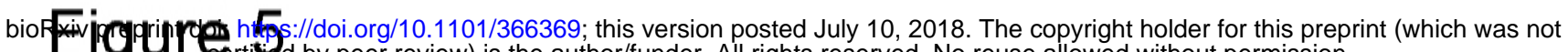

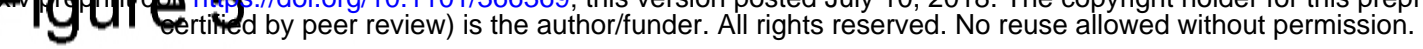

A

Prenyl-cdc42

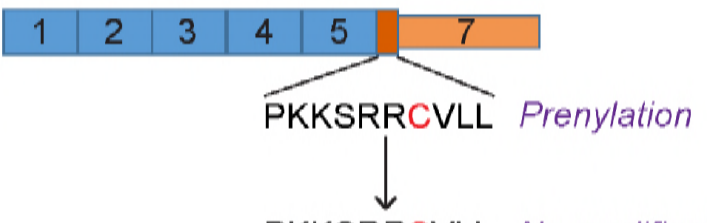

PKKSRRSVLL No modification

Palm-cdc42

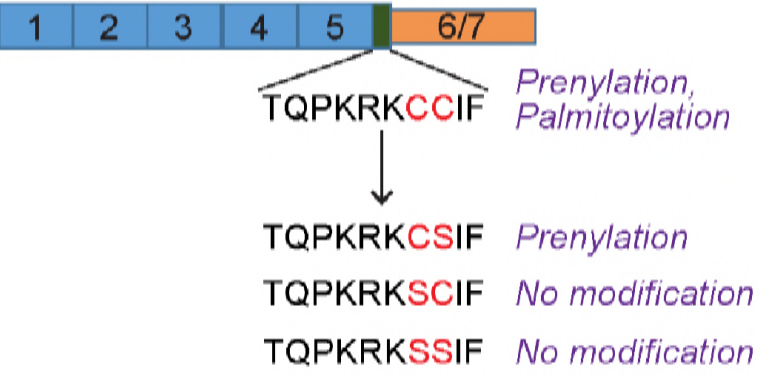

B

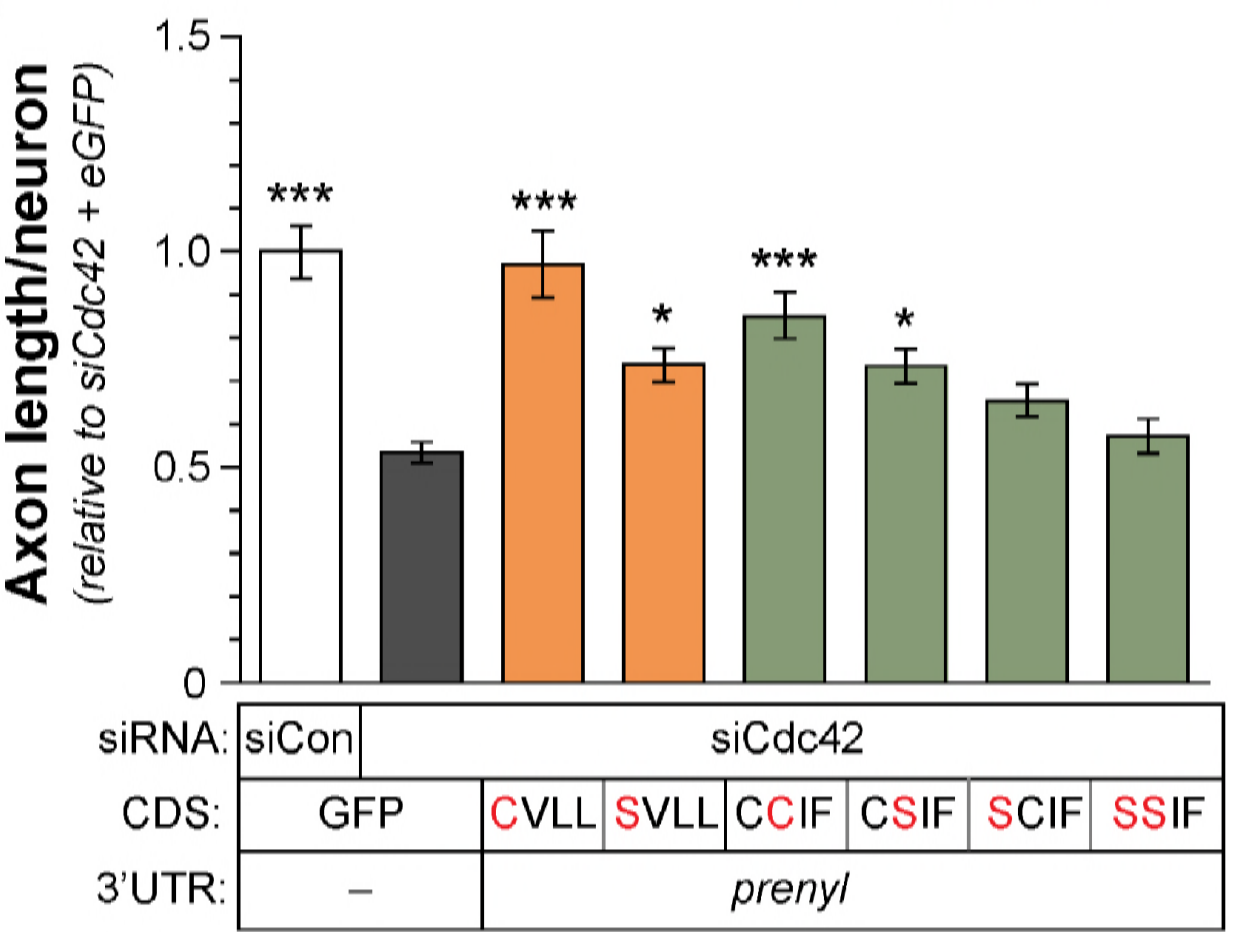

C

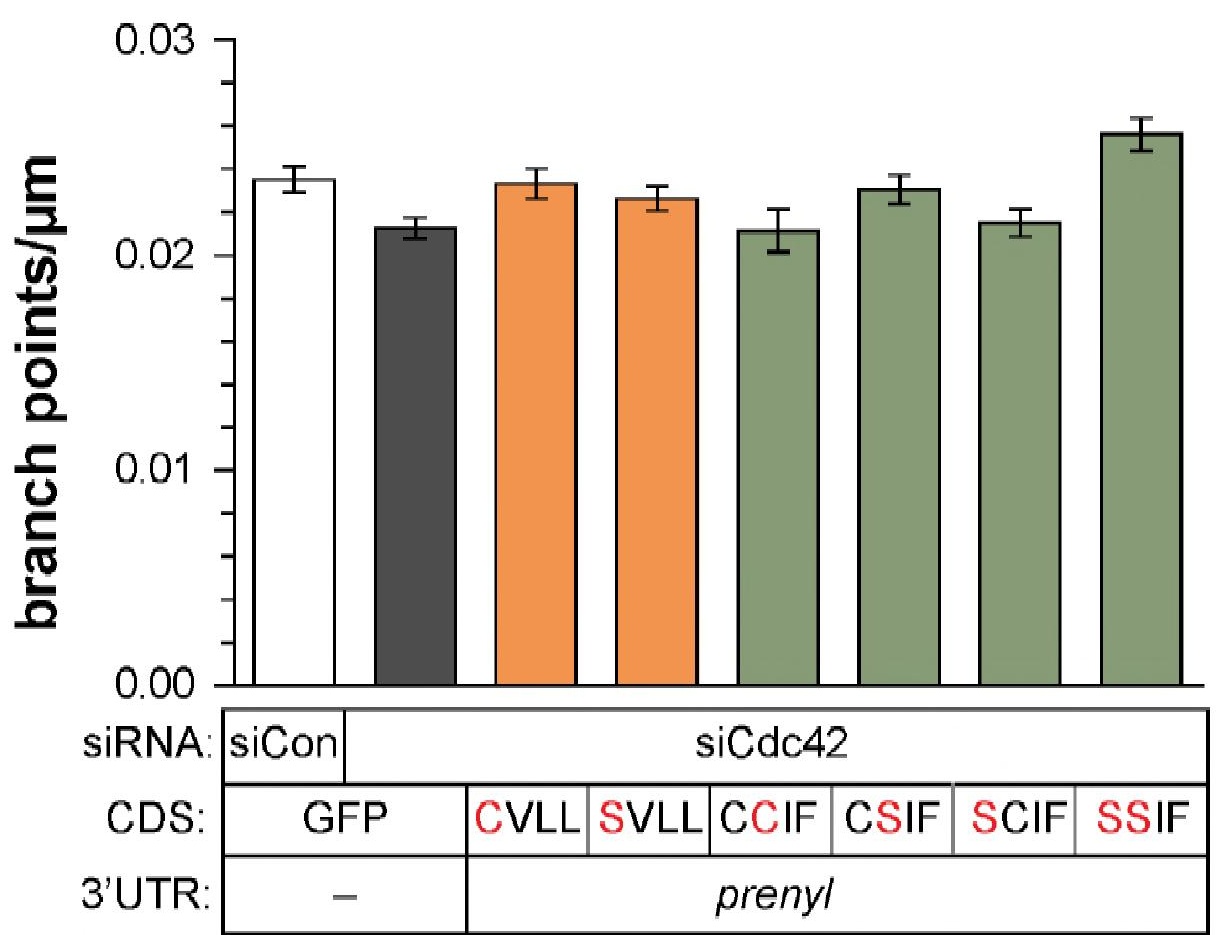

